\title{
La eficacia cultural de la comunicación de las ONGD: los discursos de los movimientos sociales actuales como revisión
}

\author{
Eloísa Nos, Amador Iranzo y Alessandra FARNÉ *
}

\author{
Propuesto: 3 de marzo de 2012 \\ Evaluado: 24 de marzo de 2012 \\ Aceptado: 28 de marzo de 2012 \\ (Abstracts y palabras clave al final del texto)
}

\section{INTRODUCCIÓN ${ }^{1}$}

El objetivo de este artículo es valorar las aportaciones de las prácticas comunicativas de los movimientos de indignación del $15 \mathrm{M}$ para un modelo de "eficacia cultural" (Nos Aldás, 2007; Pagola, 2009; Erro Sala, 2010; Santolino, 2010; Burgui, 2011) en la comunicación de las Organizaciones no Gubernamentales de Desarrollo $\left(\mathrm{ONGD}^{2}\right)$. Nuestro estudio revisa la Comunicación y el Desarrollo desde las prácticas discursivas de las ONGD españolas. El enfoque adoptado traslada el amplio acervo crítico sobre los retos comunicativos y culturales de las ONGD a la reflexión sobre los discursos promovidos desde los recientes movimientos de indignación social en España, para rescatar aquellos aprendizajes comunicativos que contribuyan a renovar la eficacia cultural de la comunicación de las ONGD.

La elección de este enfoque viene motivada por las convergencias entre los principales objetivos de comunicación de ambos actores sociales (ONGD y movimientos de indignación): la formación de ciudadanías críticas "glocales" (Halloran, 1997; Castells, 1998) y la influencia en las decisiones legislativas y políticas hacia la justicia social global. Asimismo, nos animan a escoger esta temática los efectos de movilización e introducción de nuevos temas de debate en la esfera pública de las recientes innovaciones comunicativas de los nuevos movimientos sociales (NMS). Estos acontecimientos, relativamente recientes, han llevado a las ONGD a revisar su función y su trabajo de comunicación (Ortega, 2011; Díaz-Salazar, 2011). Conscientes de la heterogeneidad de los actores sociales de los que hablamos, de sus

\footnotetext{
* Instituto Interuniversitario de Desarrollo Social y Paz (IUDESP) Universitat Jaume I de Castellón (UJI)

1 "Agradecemos a todos los miembros del IUDESP-UJI que se han implicado en procesos internos de revisión de este artículo las ideas y mejoras aportadas".

2 Usamos el término ONGD por claridad, al ser el más extendido y aceptado en la literatura especializada y en el propio sector. No obstante, el enfoque crítico será el de Tercer Sector de la Cooperación, como se definirá a lo largo del artículo.
} 
estructuras e identidades organizativas divergentes y de la complejidad y difícil sistematización de cada uno de sus escenarios de comunicación ${ }^{3}$ (en parte compartidos), apostamos por buscar relaciones significativas entre los desafíos de las ONGD y las innovaciones presentadas por los discursos de los movimientos de indignación del 15M. La finalidad última es la conceptualización de un modelo de eficacia cultural para una Comunicación de Cambio Social Empoderadora, Ecosocial y de Sostenibilidad Cultural desde la Cooperación y la Solidaridad.

La relevancia de este estudio para este monográfico se plantea desde las teorías de la comunicación latinoamericanas y en concreto las ideas de Alfaro, que centra el estudio de la Comunicación y el Desarrollo en cómo la crisis política global que vivimos (la desconfianza de la ciudadanía frente a los gobiernos, las estructuras económicas y sus medios de comunicación) reclama «sociedades en movimiento» que desafíen comunicativamente a la sociedad de la información sirviéndose tanto de las posibilidades de los nuevos entornos digitales como de la (inter) acción en los espacios públicos (2005: 57-80). Estos parámetros de análisis nos llevan a estudiar los movimientos surgidos en España en torno al 15M. Su globalidad (en diálogo con otros movimientos sociales como las protestas en Grecia o las diferentes iniciativas de los movimientos "Occupy"), heterogeneidad y carácter comunicativo, educativo y cultural presentan indicios que apuntan hacia sociedades en movimiento más allá de movimientos sociales aislados.

Para ello, este artículo se estructura en tres apartados: en una primera parte revisamos el acervo crítico nacional e internacional sobre Comunicación, Desarrollo y ONGD para enmarcar esta investigación en el estado de la cuestión de la problemática tratada y armar su marco teórico; en una segunda parte profundizamos en los desafíos de la comunicación de las ONGD desde el concepto de eficacia cultural como aportación teórica y metodológica; y en una tercera parte exploramos desde este modelo la acción comunicativa del $15 \mathrm{M}$ para rescatar las innovaciones de sus discursos útiles para la conceptualización de la eficacia cultural.

\section{REVISIÓN DEL ESTADO DE LA CUESTIÓN DE LA COMUNICACIÓN Y EL DESARROLLO DESDE EL TERCER SECTOR EN ESPAÑA}

No existe un consenso teórico en la investigación sobre esta temática, ni terminológico ni epistemológico. A efectos de nuestro posicionamiento, rescatamos de entre la diversidad de conceptos que se han propuesto como alternativas a la acepción de Comunicación para el Desarrollo los siguientes: Comunicación para el Cambio Social (Gumucio y Tufte, 2008; Barranquero, 2009), Comunicación para la Solidaridad (Aranguren Gonzalo, 2000), Comunicación para la Solidaridad y la Cooperación (Erro

3 El concepto «escenarios de la comunicación" Benavides (1992; 1993; 1996; 1997: 250), nos permite abordar los límites del discurso, los lugares sociales donde se desarrolla (Benavides, 1993: 86). Su modelo de análisis discursivo incide por igual en los contextos de emisión y de recepción (interpretación) y sus efectos desde el énfasis mismo en la "enunciación" como espacio mediador en la construcción de sentidos, valores y relaciones en su inserción en determinados contextos mediáticos y socioculturales. 
Sala y Burgui, 2010), Comunicación de Empoderamiento y Ecosocial (Chaparro, 2009). Y aquellos en los que se inspiran: Comunicación Participativa (Díaz Bordenave, 1978) y Comunicación Democrática, Liberadora, Transformativa, Alternativa, Comunitaria y Popular (Kaplún, 1985; Alfaro, 1993; 2005; Erro Sala, 2007).

Este artículo se acerca por tanto al debate sobre la Comunicación y el Desarrollo desde una revisión crítica del segundo término del binomio basada en las propuestas del Posdesarrollo, los Estudios Poscoloniales, el Ecofeminismo y la teoría de las capacidades, la libertad y la justicia (Sen, 2000; 2010, Comins Mingol y Martínez Guzmán, $2010)^{4}$. De ahí que definamos esta comunicación con Chaparro (2009: 156-157) como aquella que parte de la toma de conciencia sobre las capacidades propias del individuo para tomar decisiones de carácter colectivo [...] [desde] una escala de valores verdaderamente humana $[\ldots]$ [y] ecosocial [que incida] en la responsabilidad de instaurar un nuevo modelo económico que [...] retribuya justamente, sea respetuoso con el planeta y con la capacidad de las diferentes culturas para asumir sus destinos.

Coincidimos con Chaparro en que es necesario superar la denominación de Comunicación para el Desarrollo y apostar por otras formas de nombrar la Comunicación para así "comunicar los nuevos imaginarios y comenzar a desmontar los caducos", para favorecer escenarios de comunicación (también entre la comunidad investigadora) que den poder al ciudadano y que traten de "redefinir la simbología de significantes que han alterado los significados" (2009: 156).

En aras de la claridad expositiva, emplearemos por tanto en este trabajo el la denominación de Comunicación para el Cambio Social (como forma breve de Comunicación Empoderadora de Cambio Social) ${ }^{5}$. En concreto, revisaremos el estado de la cuestión de la Comunicación para el Cambio Social desde los desafíos comunicativos del Tercer Sector en España, centrándonos en las responsabilidades y retos de las ONGD como uno de los principales actores (interlocutores) en estos escenarios de comunicación.

Definir un concepto de comunicación para las ONGD es complejo por la heterogeneidad de tipologías de organizaciones y problemáticas que abarcan estos actores. No obstante, sus documentos fundacionales, así como los numerosos estudios sobre sus trayectorias ${ }^{6}$, delimitan una serie de particularidades que comparten como Tercer Sector, una idiosincrasia propia que las diferencia de las empre-

4 Pasamos de la acepción tradicional de desarrollo economicista y orientado desde el desarrollo tecnológico de los países en que se concentra la riqueza a un concepto actualizado de desarrollo humano que incorpora las nuevas propuestas del decrecimiento (Latouche, 2008; Ridoux, 2008) y las filosofías del buen vivir (Acosta, Lander, Gudynas y otros, 2009), que rescatan los saberes de los países empobrecidos (sobre todo de las comunidades indígenas). La concepción de "desarrollo" que este trabajo asume dialoga con los modelos de solidaridad internacional, reconocimiento, cooperación, relaciones de igualdad, de justicia y de dignidad a todos los niveles sociales y desde enfoques interdisciplinares y transversales.

5 Chaparro nos alerta de que esta alternativa de Comunicación para el Cambio Social ha sido empleada en determinados contextos también desde los fallos detectados antes en el concepto clásico de "desarrollo", como herramienta para contribuir a "acelerar el ritmo del desarrollo" (Chaparro, 2009: 154). No obstante, apostamos por su recuperación desde la transformación de esos parámetros hegemónicos del desarrollo entendido como imposición cultural y merma de las libertades (Gumucio y Tufte, 2008; Barranquero, 2009).

6 Sogge (1998), Erro Sala (2000; 2003a; 2003b), Erro Sala y Ventura (2002), Revilla Blanco (2002), Nieto (2002) o Erro y Burgui (2010), entre otros. 
sas (Mercado) y de las instituciones oficiales (Estado), como Sociedad Civil organizada $^{7}$, con una estructura estable: una gestión "privadamente pública" (Giner y Sarasa, 1995), unos objetivos de trabajo colectivo orientados al bien público y unas formas de trabajo cooperativas, por y desde la solidaridad (Nos Aldás, 2007: 210-212). En consecuencia, como reseñan sus Códigos de Conducta, las ONGD asumen una cultura comunicativa guiada desde responsabilidades educativas y de incidencia política por la justicia social y la erradicación de la pobreza (FCONGD, 1997; CONGDE, 1998).

Esta razón de ser de las ONGD se define desde lo que en inglés se denomina advocacy (Smith, 2004; 2008: 742; Dogra, 2007: 168), término difícil de traducir porque aglutina muy diversas definiciones en castellano, de las que queremos destacar aquí su combinación de una responsabilidad de sensibilización más una pedagogía política y cultural y una incidencia política, legislativa y cultural hacia procesos de cambio social. Desde esta perspectiva, las ONGD aparecen como agentes transversalmente comunicativos y transformadores que han de compaginar sus objetivos más inmediatos y concretos con una incidencia estructural y cultural a largo plazo (Cohen, 2001: 178). De ahí que en la comunicación de las ONGD se suguiera estudiar en relación con la Educación para el Desarrollo de una Ciudadanía Global, quinta generación del proyecto de la Educación para el Desarrollo (ED) (Mesa, 2001; 2010; Ortega Carpio, 2006: 4; 2007), en permanente revisión en las ciberculturas actuales para su adaptación a los nuevos estilos comunicativos, narrativos y emocionales fruto de esta "revolución comunicativa" 2.0 que propone incorporar a la educación la construcción colectiva del conocimiento (Ferres i Prats, 2010: 101).

Por tanto, el estudio de la Comunicación de las ONGD desde las capacidades, la justicia y la libertad (rasgos de la Comunicación para el Cambio Social en la que este artículo se enmarca) identifica como sus principales objetivos:

- la denuncia de las injusticias sociales con la pretensión de transformar las estructuras (sistemas) que las provocan influyendo en la configuración de una solidaridad activa (Aranguren Gonzalo, 2000) por medio de la dinamización de espacios comunicativos desde (y para) una sociedad civil informada, indignada, crítica e implicada.

- la movilización social (Martínez-Gómez y Lubetkin, 2010:142) a través de ONGD que actúen como agentes de comunicación para el cambio social (Santolino, 2010) produciendo y dinamizando "información comunicativa" desde un enfoque pedagógico e ilusionante de la comunicación vinculada también con el periodismo cívico (Alfaro, 2005: 71).

7 La Sociedad Civil incluye tanto la ciudadanía como algunas asociaciones y movimientos que no acaban de identificarse con el Tercer Sector al no alcanzar el grado de institucionalización o burocratización que su estabilidad le imprime. La Sociedad Civil cuenta con un tejido social compuesto de grupos más formales (como redes ciudadanas, movimientos sociales, grupos de voluntariado, o ONG) y otros más informales (Calle Collado: 2000), o incluso latentes. 
- la implicación (el engagement) de la sociedad civil internacional (con enfoques que van desde lo local a lo global, y viceversa) en el problema de la pobreza global, de forma que se superen los marcos de referencia ${ }^{8}$ manejados no solo por los actores con intereses privados a los que favorece la desigualdad, sino también por los modelos burocratizados de las ONGD (Darnton y Kirk, 2011).

- En conclusión, enfoques que pongan a dialogar lo comunicativo, lo educativo y lo cultural ${ }^{9}$ como flexibilización y actualización de los proyectos estancos de Comunicación, Educación, Cultura y Ciudadanía; modelos de comunicación para las ONGD que se apoyen en la eficacia cultural y la sostenibilidad cultural $^{10}$ (Erro Sala, 2010: 157; 172-173).

\section{LA EFICACIA CULTURAL DE LA COMUNICACIÓN DE LAS ONGD: ACTORES Y DISCURSOS PÚBLICOS ANTE EL RETO DE CIUDADANÍAS CRÍTICAS GLOBALES}

Esta propuesta de "eficacia cultural" se asienta en la propia cultura organizacional de las ONGD, configurada por sus objetivos de advocacy (que equipararemos a lo largo del texto a cambio social por su síntesis de comunicación + pedagogía + incidencia) vinculados a la necesidad de insertar en la "red simbólica" de la llamada sociedad informacional códigos o símbolos culturales que, en la mayoría de los casos, son un contrapunto a los que imperan en la sociedad y que sirven para legitimar y construir conductas y órdenes sociales favorables a quienes detentan más poder político, económico o "informacional"11, como nos recuerda Castells (1998: 398-402) al hablar precisamente de los nuevos movimientos sociales y su naturaleza contracultural. Se enmarca por tanto en el estudio de la comunicación de las organizaciones (Benavides, 2011) desde una planificación estratégica comunicativa (Alberto Pérez, 2003: 425) guiada por los objetivos a largo plazo de la Comunicación para el Cambio Social12.

8 Entendidos desde las teorías del framing o relaciones entre marcos cognitivos (frames) y política (Lakoff, 2004; 2008; 2010; Entman, 2007).

9 Como ya viene proponiendo Martín Barbero desde 2002 en su trabajo La educación desde la comunicación. Colombia: Grupo Editorial Norma.

10 Erro Sala aplica el concepto de eficacia cultural de Nos Aldás (2007), que se explica a continuación, y el de sostenibilidad cultural de Martín Barbero (2008) para incorporar a este debate la importancia de la diversidad cultural y de los diferentes tiempos (tempos) culturales y pedagógicos, de por sí "largos", que chocan con los del mercado o los del Enfoque del Marco Lógico (EML), a los que las ONGD están sujetas por sus modelos de financiación.

11 Entre esas historias compartidas (discursos) que mantienen determinados modelos políticos, sociales y culturales como los hegemónicos (Gramsci, 1971; Gramsci y Forgacs, 2000); esas narrativas empleadas para el control social (Hall, 2004; Mumby, 1993; 1997). De ahí que este concepto se aborde desde el análisis cultural del discurso (Hall, 1997; 2004; Galtung, 1990; 1996; 2003) y la ética comunicativa.

12 Junto a estos objetivos de comunicación estables (educativos y de incidencia por la justicia social), las ONGD, por su carácter de sociedad civil estructurada que combina una naturaleza privada con responsabilidades colectivas, también tienen objetivos promocionales y de gestión (la recaudación de fondos, la captación de otros recursos y de voluntarios y la legitimación de su estatus y su trabajo como agentes sociales). En la tensión entre parámetros comerciales y culturales entraría en juego no tanto una eficacia cultural propiamente dicha, sino una "eficiencia cultural" (Nos Aldás, 2007; 2010), porque también en los procesos comunicativos promocionales de las ONGD es importante que respeten los estilos comunicativos que su 


\subsection{HERRAMIENTAS CONCEPTUALES DE LA EFICACIA CULTURAL}

La eficacia cultural se aplica a través del estudio de la "performatividad" (Austin, 1976) de los discursos y de su acción comunicativa (Habermas, 1987) como forma de evaluar la capacidad comunicativa de las ONGD para la implicación social desde su transversalidad. La forma en que las ideas y realidades sociales se representan influye en el modo en que las personas piensan en ellas, se relacionan con ellas y actúan en consecuencia. En otras palabras, la retórica está estrechamente vinculada al modo en que los públicos piensan sobre los temas y las personas de las que habla la comunicación de las ONGD, por lo que puede jugar un papel crucial en sus comportamientos. Los discursos públicos son formas de educación informal pues participan en la configuración de la esfera pública y de los imaginarios por los que se rige.

En anteriores investigaciones venimos sistematizando este análisis de la performatividad de los discursos de las ONGD desde la eficacia (y la eficiencia) cultural a través del análisis de las campañas publicitarias de las principales ONGD españolas (Nos Aldás, 2003; 2007; 2010). Parte de nuestras conclusiones ha sido mostrar que sus discursos reflejan determinadas relaciones entre estas ONGD, sus públicos (interlocutores en los países en que son fundadas), sus contrapartes (organizaciones interlocutoras en los países en los que trabajan), los protagonistas de las situaciones de riesgo o injusticia en las que trabajan y la manera misma de entender y comunicar el compromiso social. En otras palabras, sus discursos participan en la construcción de determinadas relaciones imaginarias sobre el ámbito del "desarrollo" (o la justicia social) y en los comportamientos que éstos promueven o legitiman: cada una de las elecciones discursivas (vocabulario, imágenes, enfoque/perspectiva, personajes, formatos, estrategias...) representa "la concepción que el emisor tiene de la realidad de la que habla, su relación con esas realidades y la reacción que busca en los públicos. Cada mensaje no sólo realiza una propuesta de solidaridad determinada, sino que refleja la solidaridad del emisor y de su propia comunicación" (Nos Aldás, 2010: 15).

Esta aproximación nos lleva a los "estilos de comunicación" (O’Sullivan y otros, 1997; Erro Sala y Ventura, 2002; Sáiz Echezarreta, 2009) y a cómo éstos influyen en las creencias, valores, actitudes, emociones y comportamientos sociales y culturales a largo plazo. En esta elaboración teórica es determinante el concepto de "discursos sociales" (Benavides, 1992; 1997; 2002), que define los usos que hacen los públicos de los discursos (en función de esos estilos de comunicación), los conocimientos que adquieren de los mismos y cómo éstos pueden influir en el modo en que los interlocutores configuran las relaciones de los unos con los otros y con las realidades de las que dichos discursos hablan (Benavides, 2011) ${ }^{13}$. En este sentido, se trata de una eficacia que trabaja en el nivel simbólico, que

naturaleza de sociedad civil les reclama. Por tanto, en la planificación, desarrollo y evaluación de su comunicación publicitaria, las ONGD necesitan también ser conscientes de los efectos educativos (o des-educativos) de cada uno de sus discursos, y anticiparlos desde esa responsabilidad política y cultural a largo plazo transversal a todas sus acciones comunicativas.

13 Estas reflexiones se asientan en el carácter de mediador social y cultural que tienen los medios y los discursos y en cómo participan de la representación y reconfiguración de los imaginarios y comportamientos sociales (Hall, 1997; Vizer, 2003) proyectando determinados valores culturales (Benavides, 1997: 245-250). 
asume la importancia de los imaginarios que se manejan (construyen y legitiman) en cada sociedad como refuerzo y causa de unas determinadas conductas y que, en el caso de los emisores del Tercer Sector que trabajan en Desarrollo, precisa promover discursos alternativos activadores del tejido social y de comportamientos solidarios activos ${ }^{14}$.

La concepción de comunicación que subyace a estas ideas se asienta en el enfoque epistemológico de una Comunicación de Cambio Social hacia Culturas de $\mathbf{P a z}^{15}$. Sumamos a nuestra argumentación esta nueva perspectiva porque demuestra cómo lo simbólico incide en lo real, cómo las formas de violencia cultural legitiman, permiten y favorecen las demás formas de violencia (directa y estructural), al tiempo que es necesaria la promoción de discursos alternativos para reconocer la existencia de otros modelos culturales posibles (también legítimos) que puedan sustituir a aquellos como única forma de alcanzar verdaderas culturas de paz ${ }^{16}$.

Por tanto, el concepto de eficacia cultural incorpora de forma imprescindible la capacidad de influencia sobre la opinión pública. La demostrada dependencia de la agenda ciudadana con respecto a la agenda mediática (McCombs, 2004) y el hecho de que una gran mayoría de la ciudadanía se relacione con los asuntos públicos de esta forma mediatizada (Nos Aldás, Seguí-Cosme, Rivas, 2008: 16) conlleva la necesidad de que, para alcanzar una cierta eficacia comunicativa en términos de transformación sociocultural, estas organizaciones tengan que comunicarse con la ciudadanía, además de a través de espacios alternativos, a través de los medios de $\operatorname{masas}^{17}$.

Estos escenarios hacen aún más necesario ese aprendizaje que mire a los nuevos movimientos sociales, no tanto en el trabajo de relación con los medios, como, sobre

14 Encontramos la concreción de estos criterios de eficacia cultural en las pautas comunicativas específicas que marcan los Códigos de Conducta de estas organizaciones (CONGDE, 1998: 15-16): la comunicación de las ONGD deberá servir para "promover la toma de conciencia sobre los problemas del desarrollo; conocer y comprender las causas de la pobreza y sus posibles soluciones; la interdependencia de todos los pueblos del planeta; la necesaria reciprocidad para un conocimiento mutuo y el respeto por las diferentes culturas; y aumentar la voluntad de participación ciudadana en los procesos de cooperación para el desarrollo, fomentando el debate público necesario para impulsar políticas correctas de cooperación, intensificando la solidaridad entre el Norte y el Sur y luchando para cambiar las estructuras vigentes".

15 Esta idea parte de las aportaciones de Galtung $(1990 ; 1996 ; 2003)$ al enmarcar el "desarrollo" en su concepto de Cultura de Paz (que articula la violencia directa, la violencia estructural y la violencia cultural) e incorpora a las perspectivas de necesidades básicas los criterios de libertad, identidad, capacidades individuales y colectivas y la importancia de la cultura. Martínez Guzmán utiliza este concepto en plural, "culturas para hacer las paces" (2005), para incidir en que existen tantas formas de entender la paz como diversas son las personas y las culturas. La misma perspectiva nos lleva a articular el concepto de Ciudadanía Crítica Global de la ED en plural, ciudadanías críticas globales, como forma de reconocer la diversidad de contextos históricos, geográficos, culturales y sociales.

16 En este sentido, las ONGD jamás podrán ser eficaces culturalmente si no interactúan también con el resto de ONG. Un ejemplo actual es la creación de la Confederación Catalana de ONG por la Paz, los Derechos Humanos y el Desarrollo como suma de las tres anteriores Federaciones por separado.

17 Esto no implica caer en una adaptación acrítica a la cultura mediática establecida, que desnaturaliza y deslegitima sus propias características, sino que esta comunicación necesita interpelar la racionalidad publicitaria que impera actualmente en los discursos públicos desde una racionalidad comunicativa (Zunzunegui, 1999; Benavides, 1994; 1997), dialógica, horizontal y prestar atención a la complejidad del pensamiento frente a la superficialidad de las tendencias mediáticas. 
todo, en la innovación para captar la atención de los medios masivos ${ }^{18}$ y buscar que los discursos alternativos y propuestas encuentren grietas por las que asomarse (Giró, 1998; 2007; 2010). La clave está, como plantean Haro y Sampedro, en saber combinar, como hizo el Movimiento por una Vivienda Digna (MVD), "las prácticas de recreación de iconos de la cultura de masas y del marketing político para la difusión de las convocatorias, la atracción de la mirada de los medios de comunicación convencionales y, en suma, la búsqueda de visibilidad [...] [pero sin dejar de lado] un proceso de pedagogía política que sentó las bases para el futuro movimiento 15M" (Haro y Sampedro, 2011: 169-170).

Esta pedagogía política comunicativa, responsabilidad también de las ONGD, tiene como primer paso la indignación (Freire, 2001; Hessel, 2010). La indignación se señala aquí como una emoción moral activadora, como indicador de eficacia cultural, como "sentimiento de responsabilidad no culpable" que lleva al ciudadano a participar (Nos Aldás y Pinazo, 2010: 109), a informarse y querer informarse, a empoderarse como actor político como resultado del desarrollo de su "sensibilidad moral" (Nos Aldás y Pinazo, 2012). La sensibilidad moral define por tanto también estos procesos comunicativos hacia acciones efectivas para el cambio social y tiene como consecuencia la recuperación de una "ilusión informativa, [...] [que vaya acompañada de una] demanda comunicativa [...]" en la que son claves "información, conocimiento y comunicación" (Alfaro 2005: 65-67). En otras palabras, la eficacia comunicativa se entiende aquí como la capacidad de activar la sensibilidad moral de la ciudadanía (por medio de la indignación) como camino hacia una sabiduría cultural ${ }^{19}$.

Siguiendo las propuestas de Freire de una pedagogía de la indignación y de la esperanza como camino a la concienciación (Martínez Guzmán, 2003: 209), la articulación comunicativa de la indignación irá unida al convencimiento de poder cambiar las cosas. Los estilos de comunicación eficaces culturalmente estarán guiados por tanto por un diálogo entre emociones y argumentos, información y persuasión. Persuasión entendida con Freire $(1993 ; 2001)$ como parte de los procesos educativos transformativos que enfrentan el reto de combinar la denuncia y la esperanza en los procesos de sensibilización y de cambio. No persuasión desde planteamientos publicitarios cercanos al marketing sino a la publicity, entendida aquí como recuperación del espacio público, del enfoque colectivo, de la preocupación política de la retórica como forma de negociar diferentes identidades y propuestas políticas en esos espacios compartidos (Habermas, 1994; Benavides, 1991; 1997; Nos Aldás, Seguí y Rivas, 2008)20.

18 A través de lo que tradicionalmente se ha conocido en el ámbito profesional de la comunicación publicitaria como relaciones públicas, below the line o publicity.

19 Aplicamos aquí las ideas de Savater (2000) sobre cómo la sabiduría es la capacidad de vincular el conocimiento (que reflexiona, jerarquiza y ordena la información) con opciones vitales y valores, con cómo vivir mejor, y le añadimos el adjetivo "cultural" para enfocarlos desde las ideas de la eficacia cultural: de que sea una sabiduría que trate de trabajar desde los intereses colectivos, desde la justicia, la solidaridad y la cooperación.

20 Martínez Guzmán (2003: 209) redefine la persuasión desde la importancia en el proceso de sensibilización del convencimiento de quien comunica para lograr el convencimiento de aquel a quien se dirige y destaca cómo la "sensibilización como persuasión es sensiblemente racional y racionalmente sentimental" (2003: 209), de forma que la combinación entre información y emociones facilita la comprensión y la implicación por parte de los públicos. 
Por tanto, uno de los requisitos para este modelo es la legitimación de las ONGD ante el resto de públicos como interlocutores válidos en estos procesos de debate social y el establecimiento de redes de confianza. Esta reflexión desde la transversalidad de los estilos de comunicación y su performatividad va unida a una "sinceridad comunicativa" como propuesta de coherencia (Nos Aldás, 2010: 128-130). La sinceridad comunicativa persigue, en términos pragmático lingüísticos ${ }^{21}$, la máxima credibilidad del emisor y de sus propuestas tanto desde la veracidad de sus discursos como de su honestidad con el receptor.

En consecuencia, una comunicación eficaz culturalmente se planteará desde la responsabilidad de emisores que comparten sus planteamientos como participantes (implicados, responsables, que asumen compromisos) en los procesos discursivos. Interlocutores que no afrontan estos procesos comunicativos de forma unicamente objetivadora y distante sino intersubjetiva, dialógica y que producen discursos horizontales que persiguen cambios, resultados culturales. Por ese motivo, los discursos culturalmente eficaces no son neutrales sino que denuncian, señalan las injusticias y a sus responsables, y piden respuestas para las que proponen alternativas que solo pueden llevarse a cabo con la participación activa de ciudadanías críticas globales y con la colaboración entre todos los agentes sociales (incluidos los mercados, los estados y sus aparatos de comunicación y mantenimiento de la hegemonía socioeconómica y cultural $)^{22}$.

\subsection{LA EFICACIA CULTURAL EN LOS ESCENARIOS DE COMUNICACIÓN ACTUALES DE LAS ONGD}

Todos estos son indicadores transversales para guiar los discursos de las ONGD hacia la transformación de los imaginarios y los comportamientos culturales que perpetúan las relaciones de poder y desigualdad. Desde estos parámetros, investigadores y profesionales del sector ${ }^{23}$ vienen denunciando desde hace tiempo la tendencia a enfoques comunicativos y de cultura organizacional de las ONGD excesivamente técnico, centrado en llamadas al apoyo económico. Una comunicación por y para un modelo asistencialista, regido por la gestión de las propias organizaciones y sus proyectos técnicos más que comunicativos, incoherente e inconsistente con esa responsabilidad transversal pensada desde una comunicación pedagógica e informativa que configure escenarios empoderadores, de protesta y de acciones de cambio

21 Grice (1975; 1989) y Sperber y Wilson (1986) hablan de reglas de sinceridad, de claridad y pertinencia en las interacciones comunicativas regidas por esas máximas conversacionales (de forma que se se suponga que el emisor cree lo que dice-sinceridad-se eviten las ambigüedades y se destaque siempre la información más pertinente para el proceso de comunicación desde las perspectivas de los diferentes interlocutores).

22 Basándonos en el giro epistemológico de Martínez Guzmán $(2001 ; 2005)$ para el estudio de las Ciencias Humanas y Sociales.

23 Tanto a nivel nacional (Erro Sala, 2000; 2003a; 2003b; Erro Sala y Ventura, 2002; Ballesteros, 2001; Nieto, 2002; López Rey, 2006; Sáiz Echezarreta, 2008; Pagola, 2009; Nos Aldás y Pinazo, 2010; Erro y Burgui, 2010) como internacional (Alfaro, 1993; Sogge, 1998; Smith, 2004; 2008; De Souza, 2009; Witteborn, 2010). 
que transformen las estructuras que perpetúan los desequilibrios e injusticias. Todo esto deriva en la ausencia de una verdadera eficacia cultural transformativa a largo plazo que conforme ciudadanías globales más críticas, debido a un enfoque de gestión que relega a un segundo plano los modelos de conflicto, expresivos (Sampedro, Jerez y López Rey, 2002: 254), de resistencia creativa (García Canclini, 2010), sino que tiende a modelos comunicativos promocionales (Nos Aldás, 2003).

En este sentido, una de las principales líneas de análisis de la cultura organizacional y la comunicación de las ONGD ha sido la que incide en que las ONGD dejen de verse como "catalizadoras y movilizadoras de recursos [...] para asumir como función principal la de agentes comunicativos del cambio" (De Souza, 2009: 701; Santolino, 2010). Otra de las críticas que se repiten es la falta de sinceridad comunicativa por el "miedo al lenguaje sincero" y sobre todo a la implicación política (López Rey, 2006), la ausencia de conciencia crítica y de dimensión política, que constituye "una regresión de la acción solidaria" (García Roca, 2010: 40 basándose en las ideas de Boltanski, 2000). Una falta de sinceridad comunicativa que "ocultó los debates y las diferencias, la despolitización, y la invisibilización del trabajo educativo y cultural" (Santolino, 2010: 228). Todo esto deriva en la insistencia de la investigación y la práctica en la ineficacia y peligros de la comunicación de las ONGD al haber fomentado una solidaridad del mínimo esfuerzo (Erro Sala 2000; 2003a; 2003b; 2006, entre otros; Ballesteros, 2002; Rizzardini, 2002). Una solidaridad marcada por la privatización de las causas sociales en lugar de la cooperación colectiva para la transformación de los desequilibrios y abusos de poder que perpetúan la injusticia social. Esto es resultado de su potencial como sociedad civil estructurada, según lo cual, el bien público siempre debe estar por encima de los intereses privados (Kaldor, 2003: 23).

De ahí que podamos concluir que el análisis de las prácticas comunicativas de las ONGD españolas desde los Códigos de Conducta que las autorregulan (europeos CONCORD y otros, 2007; DEEP, 2006 y nacionales FCONGD, 1997; CONGDE, 1998), desvela la necesaria superación, en sus planteamientos discursivos, de la pena, la culpa y la caridad para apostar por la activación de una sensibilidad moral asentada en la información, la indignación y la ilusión (Nos Aldás y Pinazo, 2012) ${ }^{24}$. Así, en los últimos años, mientras algunas tendencias apuntan a prácticas que convergen con los nuevos movimientos sociales (Santolino 2010: 236-237) 25 , siguen vigentes aquellas que presentan claros problemas culturales (Pagola, 2009: 304).

\footnotetext{
24 También la eficacia del propio modelo de desarrollo implementado por las ONGD: "en las últimas dos décadas [...] se han alejado de su naturaleza fundacional, han visto limitada su capacidad de movilización social y transformación de la realidad", por lo que necesitan "re-politizar" su trabajo como "espacios de participación ciudadana y [...] organizaciones activas en la construcción de políticas públicas coherentes con los retos que plantea un nuevo modelo de desarrollo" (Secretaría técnica Plataforma 2015 y más, 2011: 1-2).

25 Una "repolitización progresiva del sector [...] Las ONGD con más capacidad de influencia (también sobre el resto de ONGD) [como Intermón Oxfam, por ejemplo], están reorientándose hacia el trabajo de lobby e incidencia política, trabajo basado fundamentalmente en una nueva gestión de la información y en la elaboración de propuestas y mensajes alternativos que promuevan el cambio de políticas" (Santolino, 2010: 236-237). Esto también se observa en algunas ONG medianas asociadas en plataformas (como la Plataforma Àgora Nord-Sud en Cataluña compuesta por Enginyeria sense fronteres, Setem, Medicos Mundi, Entrepobles y Veterinaris sense fronteres, que trabaja soberanía alimentaria).
} 
En definitiva, al analizar la comunicación de las ONGD en los escenarios de comunicación actuales detectamos prácticas heterogéneas y cambiantes, entre las que, a pesar de encontrar casos específicos que sí siguen modelos de comunicación cercanos a la eficacia cultural, son numerosos, y muy visibles, los casos que presentan indicadores de ausencia de dicho enfoque:

- Las dificultades económicas, la competitividad por los fondos y la burocratización de las entidades imprime a su comunicación un enfoque privado frente al colectivo (una tendencia a los modelos de gestión en lugar de un trabajo desde la publicity, de comunicación pública e interacción entre actores sociales que negocian y trabajan por otros modelos sociales).

- Unos estilos de comunicación que no cuidan la transversalidad de enfoques educativos que contribuyan a una sabiduría cultural en torno a los problemas del "desarrollo" en las ciudadanías del Norte por medio de una sinceridad comunicativa que denuncie, que no tenga miedo a establecer procesos de comunicación dialógicos y a proponer acciones políticas comunes.

- Una performatividad que no configura conceptos de empoderamiento ecosocial, relaciones de confianza y actitudes proactivas y prosociales sino de asistencialismo, desconocimiento mutuo y solidaridad del mínimo esfuerzo (solidaridad de consumo).

- Una ausencia de innovación comunicativa que encapsule la complejidad del pensamiento sobre estos temas en "memes" 26 eficaces que abran en la esfera pública los debates necesarios para compartir nuevas creencias que ayuden a acabar con el hambre y la injusticia social (que contagien sus propuestas a los colectivos activos y encuentren grietas en los medios de masas).

Para seguir con esta línea de reflexión, en el siguiente apartado exploramos las convergencias y divergencias entre ONGD y nuevos movimientos sociales en los actuales escenarios de comunicación y las posibles enseñanzas de la acción comunicativa de los movimientos en torno al 15M para las ONGD.

\section{APORTACIONES DE LA ACCIÓN COMUNICATIVA DEL 15M A LA EFICACIA CULTURAL DE LA COMUNICACIÓN DE LAS ONGD}

Sin obviar que no hablamos de interlocutores sociales homogéneos y fáciles de separar, y asumiendo incluso que la ciudadanía activa (activistas) a menudo puede participar de ambos escenarios simultáneamente (como así ha sido en el $15 \mathrm{M}$, en el

\footnotetext{
26 Un "meme" (adaptación al castellano del original meme) es el concepto propuesto por las teorías sobre la difusión cultural de Dawkins para nombrar la unidad (de información) cultural de transmisión (o imitación) de un individuo a otro, o de una mente a otra, o de una generación a la siguiente (Blackmore, 2000). Nos basamos aquí en el análisis del poder narrativo (narrative power analysis) propuesta por Reinsborough y Canning (2010) aplicando las teorías meméticas (Misturelli y Heffernan, 2012) de seguimiento, creación y difusión de "memes" como formas de compartir información cultural alternativa por medio de procesos virales, que han encontrado en los nuevos entornos digitales interesantes posibilidades.
} 
que miembros de las ONG han jugado un papel muy activo a título personal), estos movimientos sociales surgidos en España en la primavera de 2011, movilizados desde la indignación ante la crisis económico-política, muestran "[...] un cambio social en el que la ciudadanía está reclamando su papel activo, denunciando las falsedades del sistema" (Haro y Sampedro, 2011: 169-170), elementos clave para una reflexión comparada entre los retos detectados en la Comunicación de las ONGD y la acción comunicativa cultural de estos NMS por un sistema más justo.

Al igual que asumimos la imposibilidad de abarcar la idiosincrasia de cada ONGD, somos conscientes de la heterogeneidad del entramado de acciones comunicativas tan dispares que constituye el $15 \mathrm{M}$ como red de movimientos sociales de indignación, de la relativa proximidad de la aparición del movimiento y de su constante evolución y experimentación ${ }^{27}$. Este estudio no pretende un análisis exhaustivo del $15 \mathrm{M}$ como caso de estudio, sino que aplica a la interpretación de sus manifestaciones comunicativas el modelo en el que venimos trabajando en la comunicación de las ONGD para buscar relaciones significativas y tratar de localizar en sus innovaciones y experiencias de impacto social y cultural propuestas de revisión.

ONGD (como parte del Tercer Sector, sociedad civil estructurada) y 15M (como NMS, con estructuras cercanas a la ciudadanía, más flexibles, espontáneas y voluntarias) han de entrar en interlocución con otros actores (del Mercado y del Estado, instituciones educativas y medios de comunicación) para la articulación de unos escenarios de comunicación culturalmente sostenibles ${ }^{28}$. Estos escenarios abarcan los diferentes espacios y acciones comunicativas, educativas y político-legislativas (transformativas) necesarias para la incorporación de nuevas narrativas entre los discursos públicos.

Ya en 2002, Erro Sala, preocupado por la excesiva tecnificación de la revisión de los problemas comunicativos del desarrollo, apuntaba a los movimientos sociales como prácticas hacia las que las ONGD debían mirar. Los movimientos sociales se definen en términos de base social y ciudadanía activa, mientras que, como hemos visto en el apartado anterior, las ONGD tienden a pensar en la gente en clave económica, movilizando más su sentido de la caridad que sus competencias ciudadanas. En cambio, los movimientos sociales son manifestaciones comunicativas, que "hacen de lo comunicativo, con todo su aparato estético y espectacular, el eje fundamental sobre el que giran sus acciones [...] [; son] organizaciones pensadas desde y para una cultura audiovisual y mediática, pero que también hacen de la comunicación su estructura para la participación y la organización social" (Erro, 2007: 3).

27 Destaca su actualidad y su continuidad en el tiempo, con diferentes llamamientos sociales: el 19J ("¡Toma la calle! NO al pacto del Euro"), el 150 ("150 Unidos por un \#cambioglobal” en su dimensión internacional "United for Global Change \#15oct") y, ya en 2012, el 19F ("Bloque crítico Contra la Reforma Laboral"), el 24F ("No rescates a bancos 24F”) y el próximo 12M ("Mayo 2012 ¡Volvemos a la calle!” y "12M-15M Reload"). A estas se suman otras convocatorias nacionales y locales contra los recortes en los servicios públicos en 2012 coordinadas desde las asambleas de diferentes ciudades.

28 Como afirma Santolino: "una vez reconstituidas comunicativamente [las ONGD] no podrán ignorar ni las dinámicas ni al resto de actores que se mueven en el sistema informativo, educativo y cultural, o bien para establecer sinergias, o bien para identificar y neutralizar las prácticas contrarias a la conformación de una ciudadanía global crítica” (2010: 240). 
Un ejemplo muy claro de esto se encuentra en los lemas empleados por estos movimientos desde el $15 \mathrm{M}$, que subvierten los rasgos de miedo a la sinceridad de algunas ONGD y sus enfoques mercantilistas, y construyen nuevos lenguajes virales planteados desde lo comunicativo y lo educativo ("Vamos despacio porque vamos lejos"; "Hemos sido hijos de la comodidad, pero no seremos padres del conformismo"; "Apaguemos la tele, encendamos la mente"; "Estamos reflexionando, perdonen las molestias"; "Ayer estaba indignada, hoy estoy ilusionada"; "Pienso, luego estorbo"), desde lo creativo ("Crisis significa cambio, let's dance", "Ya está bien de estar mal"), desde nuevos modelos basados en la confianza ("No estamos en contra del sistema, queremos cambiarlo"; "Ni cara A ni cara B, queremos cambiar de disco"; "Construyamos un sistema en el que creer"), que a menudo interpelan la racionalidad publicitaria y los discursos ya conocidos desde el diálogo ("Yes we camp", "Spain is different, not indifferent"; "Bienvenido a la república independiente de mi plaza"; "No quiero un iPod nuevo, quiero una vida nueva"; "Fresh Camping. Tu campa, y cada día el de + gente").

Sintetizando todo lo anterior, nos preguntamos con Barnhurst (2011: 584) cómo imaginan la política y la comunicación las movilizaciones del $15 \mathrm{M}$ y qué huellas de esas imágenes dejan en sus acciones: cómo se concibe y representa el movimiento $15 \mathrm{M}$ (cuáles son sus discursos), qué relaciones establecen con las temáticas que tratan y con sus interlocutores y qué reacciones buscan desde dichos escenarios. Este estudio exploratorio de los discursos del $15 \mathrm{M}^{29}$ se estructura desde los criterios de análisis cultural extraídos de la revisión teórica para seguir avanzando en la conceptualización e implementación de los enfoques de eficacia cultural en el ámbito de las ONGD:

\section{*Los discursos del $15 \mathrm{M}$}

Sus estrategias discursivas de configuración de sentidos, valores y relaciones persiguen formar una ciudadanía crítica global (en concreto a través de la española), por medio de la deslegitimación de las injusticias sociales y la defensa de un nuevo orden económico, social y cultural más equitativo, basado en criterios éticos y de transparencia, de igualdad, de derechos sociales, de desmilitarización, pacíficos, ecológicos, participativos, deliberativos, de empoderamiento. Estas ideas están presentes en muchos de los documentos que han producido, en concreto, en el "Manifiesto" de Democracia Real Ya (DRY), uno de los movimientos originarios y con más presencia discursiva del $15 \mathrm{M}^{30}$, y en los lemas seleccionados para sus pro-

29 Las principales fuentes de este estudio han sido: los lemas mostrados por el movimiento en sus manifestaciones, la web de Democracia Real Ya (http://www.democraciarealya.es/), el Facebook del 15M (http://es-es.facebook.com/Mov15M), los grupos relacionados al 15M en la red social N-1 (https://n-1.cc/), así como los enlaces y noticias producidas por Sol TV y el canal de Youtube de DRY, localizadas a menudo a través de su seguimiento en Twitter y su presencia en los siguientes medios tradicionales: El País, El Mundo, Abc y Público, aunque solo se incluirán en la redacción final del artículo los más significativos.

30 El movimiento se presenta como colectivo heterogéneo y muestra de la ciudadanía, reunida porque "todos estamos preocupados e indignados por el panorama político, económico y social que vemos a nuestro alrededor. Por la corrupción de los políticos, empresarios, banqueros...". Su eslogan final resume la articulación y el desarrollo del movimiento que empieza por la indignación y reivindica la posibilidad y el derecho 
testas en las calles, que activan determinadas emociones vinculadas con la implicación, la indignación, la ilusión, la esperanza y el convencimiento ${ }^{31}$.

Estos textos se plantean desde las máximas de relevancia, calidad y claridad (Grice, 1975), aportando a los ciudadanos interesados la información necesaria y buscando formas de implicarles sin perder el carácter directo. Una de las principales estrategias en este sentido es la denuncia de las injusticias sociales con la pretensión de implicar a las multitudes en las acciones necesarias para la transformación de aquellas estructuras (sistemas) que las provocan, perpetúan y legitiman. Algunos de los lemas que visibilizan estas ideas son: "No es la crisis, es el sistema"32, "Error del sistema", "Error 404. Democracia not found", "iLa democracia 1.0 necesita actualizarse! Actualizando democracia 2.0: Loading", "No son rescates, son chantajes. Vuestra crisis no la pagamos", "No hay pan para tanto chorizo", "No somos mercancía en manos de políticos y banqueros","No nos falta dinero nos sobran ladrones"). No obstante, al mismo tiempo, como interpelación a una de las tendencias mediáticas de deslegitimación de estos movimientos (la asociación al marco de radicalidad "antisistema") se emplean otros como: "No somos antisistema, somos cambiasistema", "No soy antisistema, el sistema es anti-yo/anti-nosotros/as", "No estamos en contra del sistema, queremos cambiarlo".

\section{*De los discursos a las relaciones. Redes de confianza (transparencia y sin- ceridad comunicativa)}

Los movimientos sociales se caracterizan, precisamente, por fraguarse mediante la comunicación directa entre ciudadanos activos, y por expandirse en círculos concéntricos interpersonales basados en la confianza y la presunción de veracidad (Nos Aldás, Seguí y Rivas, 2008: 17). Un ejemplo de redes de confianza para la participación ciudadana y los movimientos alternativos que se ha expandido con el $15 \mathrm{M}$ es el caso de $\mathrm{N}-1^{33}$. Desde un punto de vista organizativo, se estructura en un semillero de redes colaborativas, inspiradas en el concepto de rizoma (Deleuze y Guattari, 1988), como la capacidad de estar interconectados sin ser ni uno ni múltiple, sino multiplicidades, algo que no empieza ni acaba, sino que siempre está en

\footnotetext{
a participar en la construcción del cambio ("Por todo lo anterior, estoy indignado. Creo que puedo cambiarlo. Creo que puedo ayudar. Sé que unidos podemos. Sal con nosotros. Es tu derecho"), desde el convencimiento de que la situación no es inevitable ("Creo que puedo cambiarlo") y que se puede contribuir tanto a nivel individual como colectivo.

31 "Una sonrisa viaja más lejos"; "Democracia 1.0 obsoleta, Democracia 2.0 instalándose, $5 \%$ buffering"; "Hay noches que todavía sueño", "Somos la levadura que levantará la masa", "Somos neuronas de un planeta vivo, conectémonos", "Pienso, luego me indigno", "Sin tele, sin cerveza, toma la plaza con cabeza". Los diferentes lemas citados en el análisis de este artículo se han extraído de: Democracia Real Ya (http://www.democraciarealya.es/), Facebook del 15M (http://es-es.facebook.com/Mov15M), www.consumehastamorir.org "Recopilación de lemas y pancartas del movimiento 15M"

(http://www.letra.org/spip/spip.php?article4060) y blog La Telaraña Digital. Revista Cultural Independiente (http://latelarana.wordpress.com/2011/07/12/lemas-y-disenos-de-la-spanishrevolution-y-el-15m/); "Primer Album de Lemas del 15M (200 lemas)"

(http://www.facebook.com/media/set/?set=a.10150200788689399.328032.187580034398).

32 Que forma parte incluso del logo de la "SpanishRevolution".

$33 \mathrm{https://n-1.cc/:} \mathrm{una} \mathrm{red} \mathrm{social} \mathrm{libre,} \mathrm{que} \mathrm{se} \mathrm{define} \mathrm{como} \mathrm{un} \mathrm{dispositivo} \mathrm{tecnopolítico} \mathrm{sin} \mathrm{ánimo} \mathrm{de} \mathrm{lucro,}$ un proyecto basado técnicamente y conceptualmente en el Software Libre, donde los participantes comparten valores como la libertad, la transparencia, la colaboración, la creatividad y el conocimiento compartido.
} 
medio. Pretenden una manera alternativa y autogestionada de colaborar y crear contenidos, que permite, entre otras cosas, obviar los problemas de dependencia, vigilancia o censura de las plataformas comerciales.

De este modo, las tecnologías de la información y la comunicación (TIC), especialmente los entornos 2.0, se han manifestado como el escenario perfecto para facilitar estas exigencias de una comunicación culturalmente sostenible, entendidas desde sus estilos comunicativos de cultura del compartir (o shared culture), como revolución hacia la creación colectiva de conocimiento, uno de los rasgos de la "cibercultura" (Levy, 2007) del $15 \mathrm{M}$, que tiene en la inteligencia colectiva uno de sus principales motores:

La puesta en sinergia de las competencias, los recursos y los proyectos, la constitución y el mantenimiento dinámico de las memorias comunes, la activación de modos de cooperación flexibles y transversales, la distribución coordenada de los centros de decisión, se oponen a la separación estanca de las actividades, a la compartimentación, a la opacidad de la organización social (Levy, 2007: 13).

El 15M como NMS se apoya y apropia de las TIC (Marí Sáez, 2011) y se configura también en red, como estructuras descentralizadas con una organización interna menos jerárquica y más democrática y participativa que otras entidades, como las ONG o los partidos políticos, consiguiendo atraer a más ciudadanos, que de otra forma no participarían, y llegando a tener una base más heterogénea (Riechmann y Fernández Buey, 1994: 61-67; Requena Santos, 2008: 64-67) en la que se han involucrado redes que ya venían trabajando en estas temáticas y redes nuevas.

\section{*De las relaciones a las reacciones}

Las consecuencias performativas (perlocucionarias) de los discursos del $15 \mathrm{M}$ (las reacciones que motivan) y sus discursos sociales (los usos que los públicos hacen de ellos) nos llevan a analizar su vertiente movilizadora (su capacidad de movilización), ya que, la movilización sin discurso no sería posible, pero el discurso sin movilización sería infructuoso. La importancia de la participación ciudadana en la construcción conjunta del movimiento es un rasgo recurrente en el discurso del $15 \mathrm{M}$, que alienta constantemente a la participación ${ }^{34}$.

Si al apoyo ciudadano con el que cuentan los NMS (el 15M) por su condición de redes de confianza, como hemos visto, le integramos el uso de las TIC y de los entornos 2.0, resulta un poder de convocatoria y de movilización muy elevado, que a su vez se amplifica en su ocupación (entendida como reapropiación) del espacio

\footnotetext{
34 Como hemos visto en el manifiesto de DRY, este concluye con una última exhortación, de la primera persona del plural a la segunda del singular, a participar y movilizarse en la calle en forma de la invitación directa: "Sal con nosotros. Es tu derecho". Además, en la web de DRY se contempla un apartado específico "Participa", donde la plataforma explicita varias maneras de participación de la ciudadanía y fomenta la interacción (como inscribirse a la base de datos de colaboradores, ayudar en la organización de las manifestaciones de los grupos locales, seleccionar los mejores lemas para la manifestación, el envío de dudas y consultas, así como de artículos o propuestas sobre la actualidad económica). Al presentar las "Propuestas", no se imponen como medidas cerradas, sino que se fomenta el intercambio de ideas con “¡Opina sobre las mismas y propón las tuyas en el foro!”. De la misma manera, el Facebook del 15M registra mucha actividad no solo por las publicaciones del movimiento sino también por la participación de particulares y colectivos, que comentan y etiquetan las noticias y a su vez ofrecen información de varios tipos, documentándola con enlaces, imágenes y vídeos.
} 
público ${ }^{35}$, ejemplificando el dinamismo que se puede generar en los contextos del mundo social a partir del mundo parasocial (Aladro Vico, 2011: 91-92), o, como explica Alfaro, cómo las sociedades se están moviendo desde los entornos 2.0 entre "la calle virtual y la real" (2005: 67), y viceversa, ya que los lemas de las acampadas también apelan a quienes les observan por las pantallas masivas: "¿Qué les vas a decir a tus hijos cuando te pregunten dónde estabas? ¿Viendo la tele?’. Destaca por tanto la capacidad del 15M para movilizar a las multitudes (Hardt y Negri, 2004; Sampedro, 2005; Haro y Sampedro 2011; Sampedro y Sánchez Duarte; 2011), para sacar a la gente a la calle, a partir de todo un entramado de discursos adaptados a muy diferentes necesidades, momentos y colectivos (a diferentes escenarios de comunicación, principalmente mediante el uso de diferentes redes sociales y formas de comunicación viral). La movilización es básica para sustentar la estrategia comunicativa porque demuestra que hay mucha gente que comparte esos principios, que realmente sí es posible cambiar la situación actual (confianza que demuestran lemas como el de "Somos el 99\%").

Para esto, los discursos del 15M pasan del "nosotras [las ONGD, como intermediarias] lo hacemos por ti" (una solidaridad mediada, cómoda) a acciones comunicativas que implican desde el empoderamiento, que reclaman que lo hagamos entre todos y todas: "No nos mires. Pregunta. A ti también te afecta"36. O apelan a la responsabilidad colectiva: "Haz que tus abuelos se sientan orgullosos", "Va por ti, abuelo!"37. Todas estas estrategias discursivas derivan en una sensibilidad moral que activa (o dialoga con) la indignación (como emoción moral de responsabilidad no culpable) lo que conlleva mayor demanda de información al tiempo que la producción de información comunicativa (autocomunicación) y que es constantemente compartida desde un enfoque de justicia social. En otras palabras, se produce un incremento de la demanda comunicativa (desde esa ilusión informativa creada por la comunidad y sus iniciativas y por la falta de confianza en los poderes fácticos, que deriva en la búsqueda independiente de información, como han demostrado Shepherd y Kay, 2012). Uno de los lemas que refleja esto es "Otra política es posible, queremos respuestas".

\section{*Dimensión discursivo-política y resultados socioculturales}

Estos son ejemplos de publicity, espacios comunicativos dinamizados desde (y para) una sociedad civil informada, indignada, crítica, activa y que trabaja desde lo colectivo. Desde que el $15 \mathrm{M}$ se puso en marcha, las iniciativas de (ciber)activismo y (ciber)democracia "real" en las calles y las redes sociales se han multiplicado. Iniciativas específicas de solidaridad activa y movilización social han sido: “¡Toma la calle!", "No les votes", "Graba tu pleno", "Stop desahucios". Estas además se han canalizado en propuestas que a su vez se han transformado en peticiones específicas

\footnotetext{
35 Algo que ONG medioambientalistas como Greenpeace siempre han tenido muy claro.

36 Un grupo de Facebook se llama "Yo soy un/a joven español/a que quiere luchar por su futuro" y en la página web de DRY aparecen ejemplos como: "Si todos nos unimos, podemos cambiarla", "construir entre todos una sociedad mejor", "Es hora de ponerse en movimiento", "Sin nosotros nada de esto existiría, pues nosotros movemos el mundo" "Podremos eliminar los abusos y carencias que todos sufrimos", "Reclamar sus derechos y pedir una auténtica democracia", "Ahora somos nosotros, la gente, quienes decidimos nuestro futuro", "Because we are one voice, heart, world".

37 Mantenemos la transcripción exacta del original.
} 
de reformas legislativas a través de la plataforma Actuable, en la que participan también $\mathrm{ONGD}^{38}$. Su eficacia de movilización, incidencia política e impacto legislativo se observa sobre todo en la aprobación el 9 de marzo de 2012 de un Real Decretoley por el Gobierno para evitar desahucios ${ }^{39}$.

En estos escenarios socioculturales y digitales, por tanto, la "autocomunicación de masas" (Castells, 2009) ha sido clave. La ciudadanía ha creado sus propios contenidos y sistemas de información y comunicación ${ }^{40}$. Éste es uno de los rasgos vertebrales para abordar lo que pueden aprender las ONG de movimientos como el $15 \mathrm{M}$, ya que, como señala Nachawati desde su experiencia como comunicadora en estos escenarios, "[...] de un contexto en el que los grandes medios determinaban qué era noticia hemos pasado a un contexto en el que ciudadanos bien organizados pueden atraer atención global hacia sus historias" $(2012: 84)^{41}$. Una de las principales características de esa autocomunicación, por tanto, es cómo esas redes alternativas de comunicación contribuyen a fijar nuevos temas en la agenda mediática y política (Martínez Avidad, 2011) ${ }^{42}$. Ponen en marcha mecanismos para desafiar la versión oficial a través de la construcción de marcos alternativos, no solo por el carácter crítico de sus mensajes hacia las estructuras de dominación y poder, sino sobre todo por ser en sí mismas "medios de expresión de la ciudadanía, un espacio similar a la esfera pública imaginada por Habermas" (Martínez Avidad, 2011: 279).

Se observa en estos escenarios "la proliferación de prácticas y discursos contrahegemónicos" producidos por los movimientos del $15 \mathrm{M}$ que han abierto debates entre amplios públicos sobre cuestiones estratégicas: “¿Cómo inventamos una sociedad alternativa que sea verdaderamente democrática? ¿Qué organización social

38 La reforma de la Ley Electoral (“una persona, un voto"); un referéndum para ratificar la reforma de la Constitución sobre el límite de déficit; una Ley de Transparencia para el acceso a la información pública; evitar la criminalización de la protesta civil, una de las que ha obtenido más apoyo; la paralización de los embargos o la inclusión de una casilla del 0,7\% del IRPF para la ciencia (http://www.actuable.es/peticiones).

39 Real decreto-ley 6/2012 de medidas urgentes de protección de deudores hipotecarios sin recursos. (hHp: www.boe.es/boe/días/2012/03/10/pdfs/BOE-A-2012-3394.pdf). Incluía como anexo un código de buenas conductas al que, de forma voluntaria, se han adherido la gran mayoría de las entidades financieras que conceden préstamos hipotecarios en España. En marzo de 2011, la Plataforma de Afectados por la Hipoteca (PAH) y el Observatori de Drets Econòmics, Socials $i$ Culturals (DESC), junto a otras entidades, empezaron la tramitación de una iniciativa legislativa popular (ILP) para regular la dación de pago con efectos retroactivos. La recogida de firmas, iniciada en abril de 2012, anima a participar: “¡Llenemos otra vez las calles y las plazas! ¡A por todas! ¡¡A por ellos!! ¡i¡Sí se puede!!!” (http://afectadosporlahipoteca.wordpress.com/ilpiniciativa-legislativa-popular/ [consultado el 21 de abril de 2012]).

40 https://n-1.cc, bookcamping.cc y todos los grupos de Facebook, canales de Youtube, perfiles de Twitter, por ejemplo.

41 Un claro ejemplo es la producción diaria y difusión continuada de viñetas y humor gráfico por la iniciativa "Humor indignado 99\%" en Facebook, muestra de análisis y reflexión creativa de las preocupaciones y propuestas del 15M.

42 Para ello es determinante la interpretación de los medios de comunicación tradicionales, actores imprescindibles para el cambio social y que forman parte tanto del problema de la crisis política y económica como de la solución. Nos basamos para ello tanto en la teoría crítica de Chomsky y Herman (1995) y su "modelo de propaganda" como en sus revisiones por autores como Curran (2005), que opone a los "filtros" de los que hablan Chomsky y Herman, y que limitan las informaciones que los medios ponen a disposición de sus audiencias, la existencia de "contrafiltros" que permiten la difusión de perspectivas críticas en los medios. También Giró $(2007,2010)$ señala que los grandes medios presentan grietas por las que se cuelan visiones 
puede sustituir al capitalismo actual? ¿Qué tipo de organizaciones políticas y sociales necesitamos?" (Fernández González, Sevilla Alonso y Urbán Crespo, 2012: 911). Para ello, han utilizado diferentes memes para iniciar procesos virales a través de sus diversas plataformas y acciones de comunicación, al tiempo que han difundido y amplificado otros contenidos producidos por movimientos similares (como "Occupy" o "We are the 99\%") 43 . El principal meme marco que el $15 \mathrm{M}$ ha manejado (y mantiene como base) como activador y propuesta de estos escenarios de debate es el de la indignación: “EEstamos indignados!”. Este ha sido su discurso principal para desactivar los mitos de control del poder hegemónico y promulgar otros alternativos. Un recurso discursivo que en la línea del resto de sus lemas dialoga con una expresión cotidiana, que cualquier ciudadano utiliza o ha utilizado cuando algo de verdad le importa y le provoca una emoción movilizadora.

Un lema que sintetiza y visibiliza muy bien esta idea memética de instauración de nuevos debates públicos, es el siguiente: "Nadie podrá descolgar estos mensajes de tu mente cuando caiga el último cartel". Otro de los más destacados es "Esto solo lo arreglamos SIN ellos" (que desde las posturas pacíficas e inclusivas del movimiento ha evolucionado retóricamente hacia un "Esto solo lo arreglamos entre todos"). Una llamada a sustituir a las actuales élites dirigentes. Es decir, no se trataría tanto de excluir a los actores sociales que ocupan el poder como de sustituirlos por aquellos dispuestos a desarrollar las políticas que realmente interesan a la mayoría. Es un lema que se puede vincular también al del "Somos el 99\%" (es decir, las élites no representan ni defienden los intereses de la mayoría). En todo caso, es un lema que llama a la acción, a la actuación, que incita a la actividad conjunta, lo que contrasta con el tipo de reacciones que fomenta la comunicación de las $\mathrm{ONG}^{44}$.

\section{*El impacto en los medios de comunicación de masas y su interpretación de los discursos del movimiento}

El último aspecto que queremos analizar es, precisamente. la interpelación a los grandes medios de este trabajo discursivo-político de movilización en las redes sociales y en las calles y de creación de nuevos marcos semánticos de referencia para el debate público y político. La movilización en las calles y en las plazas (principalmente lo que en el $15 \mathrm{M}$ se inició con Acampada Sol y Acampada

críticas y Castells (2009), por su parte, destaca el papel de los medios de comunicación como "el espacio donde se crea el poder", es decir, "el espacio en el que se deciden las relaciones de poder entre los actores políticos y sociales rivales" (262). Esto se combina con la integración del modelo de activación en cascada de Entman (2004) (5 elementos: gobierno, otras elites, medios de comunicación, marcos de información y público) con el modelo de sociedad red de Castells (2009), añadiendo al anterior las redes alternativas de comunicación, que se interrelacionan con el público, conformando un sexto nivel en la activación.

43 Algunos de los memes más característicos han pasado de lemas a convertirse incluso en grupos de trabajo (como por ejemplo "No hay pan para tanto chorizo", con perfil en Facebook, y que también ha funcionado de forma viral en todas las manifestaciones a nivel nacional que se han producido en las diferentes ciudades durante el año 2012 por los recortes en la Educación y la Sanidad Pública).

44 Esa solidaridad del mínimo esfuerzo. Un ejemplo es la actual campaña de Médicos Sin Fronteras "Pastillas contra el dolor ajeno", que a pesar de su presencia y viralidad por redes sociales, solo solicita un gesto fácil (que te gastes un euro en comprar sus pastillas) para apoyar en su financiación, sin llamar a un compromiso mayor que posibilite un cambio estructural (con lemas además más individualistas como "Grita de dolor", "Ponte en tratamiento"). 
Barcelona) se convierte en un factor de atracción para los medios de comunicación de masas que, aplicando sus criterios de noticiabilidad ${ }^{45}$, no pueden obviar la presencia de multitudes en la vía pública. No obstante, cada medio, en función de su orientación ideológica (Hallin y Mancini, 2004), recoge y presenta esta información de muy diferentes maneras. Así, por ejemplo, en el caso del $15 \mathrm{M}$, mientras el diario $A b c$ utilizó un marco de conflicto para hablar de las manifestaciones, y no reflejó sus propuestas, Público mostró una "sociedad en movimiento" (Alfaro, 2005), compuesta por individuos activos e implicados en el cambio social y dio espacio a sus debates ${ }^{46}$.

Llegar a los medios de comunicación es importante, porque, en la medida en que estos dan relevancia a un asunto, sus audiencias asumen esa importancia (McCombs y Shaw, 1972; Scheufele y Tewksbury, 2007). La convicción del movimiento sobre la importancia de este aspecto y su efectividad al respecto se encuentra, no solo en la retórica y enfoques de sus lemas, sino también en algunos de los temas presentes ya en la primera ocupación de Sol: "Si no salimos en los periódicos, saldremos en los libros de historia", "Sin botellón no nos sacan en la televisión” o "¡Periodistas! Sed valientes y contad la verdad". Se constata además en la presencia de Comisiones de Comunicación dentro de las Acampadas desde un primer momento así como en el esfuerzo en la red N-1 por formarse en comunicación, relacionarse con los medios y hacer seguimiento y analizar todas las informaciones que aparecen en los mismos sobre el $15 \mathrm{M}$ y cada una de sus acciones y grupos (existe una Comisión de análisis, con diferentes grupos de trabajo).

Como hemos visto, encontramos un ejemplo muy claro de la dificultad de conseguir un impacto cultural a través de dinámicas comunicativas que promuevan narraciones alternativas y las visibilicen en el espacio público en las reacciones e interpretaciones que los medios más lejanos ideológicamente al movimiento han realizado, e incluso la tendencia al desprestigio y la deslegitimación a través del marco de conflicto mencionado. Después de las manifestaciones del 15O, ha habido otros casos en los que determinadas protestas se han asociado de forma genérica a actos de incivismo por parte de algunos medios de comunicación. De esta forma, las manifestaciones no se reconocen como un acto legítimo de libertad de expresión,

\footnotetext{
45 Los criterios de noticiabilidad elaborados por diferentes teóricos, empezando por estudios clásicos como el de Gans (1979), señalan el número de personas afectadas como uno de los factores que marcan que un hecho se convierta en noticia.

46 En las movilizaciones del 15 de octubre de 2011 en todo el mundo, la portada de $A b c$ del 16 de octubre está ocupada en sus tres cuartas partes por una imagen a color de los disturbios ocurridos en Roma (un joven descamisado y enmascarado lanza al aire un extintor mientras a sus espaldas arde un vehículo). Uno de los editoriales del día del diario ubica el movimiento desde el conflicto: "la ocupación incontrolada de espacios públicos no es el camino". Al contrario, Público actúa de altavoz de los manifestantes: ofrece una gran cantidad de testimonios, consignas coreadas y pancartas exhibidas ( $A b c$ no recoge en sus páginas declaraciones de los indignados). Público muestra en su portada una decena de fotografias de indignados de diferentes edades y condición social, cada uno con una pancarta en un idioma distinto (" $0 \%$ interest in people", "We are the 99\%", "Indignez vous!", "Rebeldes sin casa", "The end is nigh", entre otras). En las dos primeras páginas interiores vuelve a dar voz a los indignados con testimonios ilustrados con la fotografía de su autor, su nombre y su profesión (la actitud de los retratos es pacífica y muchos de ellos aparecen sonriendo). La visión favorable al 15M en Público se ve también en sus columnistas (Marco Schwartz advierte en su artículo que "cualquier político sensato" debería tomar en serio los movimientos de protesta).
} 
sino como situaciones que ponen en peligro la paz social ${ }^{47}$. Estas narrativas legitiman decisiones posteriores como la que se ha visto planteada en este caso de una propuesta de reforma del Código Penal que incluiría la criminalización de las protestas ciudadanas ${ }^{48}$. Esto nos lleva a insistir en cómo la incorporación de las propuestas de los NMS por la justicia social a nuestras culturas precisa de la interacción entre todos los actores sociales, incluidos los medios de comunicación de todo tipo (junto a los agentes políticos, los legislativos o los económicos), por lo que es muy reseñable también la expansión en paralelo a Democracia Real Ya de iniciativas como Periodismo Real Ya o Periodismo Ético Ya ${ }^{49}$.

En definitiva, ésta es la actualidad de la Comunicación para el Cambio Social: esos "desafíos a la sociedad de la información" (Alfaro, 2005) por las multitudes inteligentes (Rheingold, 2002; Navarro y García Matilla, 2011) que a su vez son precisamente las aspiraciones comunicativas de las ONGD que más frustradas se ven por sus paradojas estructurales: la fuerte vinculación de una gran parte de las ONGD con el Estado y su herencia de modelos comunicativos y de gestión del Mercado dificultan su acción contracultural a través del planteamiento de estos debates y participación abierta en los mismos. Sus mensajes apenas plantean la opción de apadrinar o colaborar ${ }^{50}$ con una ONGD, pero no abren debates amplios sobre las cuestiones estructurales.

\section{CONCLUSIONES FINALES}

El estudio aquí presentado destaca las vinculaciones del movimiento de indignación colectiva $15 \mathrm{M}$ con el ámbito de la Comunicación para el Cambio Social y los agentes que trabajan en ella, por su producción de discursos que incorporan tanto la protesta como la propuesta desde posturas pacíficas y colaborativas que se identifican con la naturaleza misma de la comunicación pública o colectiva (publicity). Los

47 Un ejemplo reciente son las protestas de los estudiantes del instituto Luis Vives de Valencia (febrero de 2012), que el diario Las Provincias las situó dentro de un marco de conflicto, al asociar las reivindicaciones con incidentes y subrayar la presencia policial con titulares como "La jornada de protestas de los estudiantes deja diez detenidos" o "Tres concentraciones no autorizadas dejan al menos un policía herido al intentar bloquear el tráfico en el centro" (http://www.lasprovincias.es/v/20120217/valencia/jornada-protestas-estudiantes-deja-20120217.html) [consultado el 17 de abril de 2012].

48 El ministro del Interior avanzó el 11 de abril de 2012 algunas de las medidas que su ministerio estaba estudiando dentro de una amplia reforma del Código Penal y que incluía medidas contra los movimientos que actúan de forma concertada y con técnicas de guerrilla urbana y tipificar como "delito de organización criminal" las acciones que tengan como finalidad "alterar gravemente el orden público" y las que, con tal fin, se concierten por cualquier medio de comunicación, como Internet

(http://www.lavanguardia.com/politica/20120411/54284295774/interior-necesario-aumento-penas-anteespiral-violencia.html) [consultado el 17 de abril de 2012].

49 Otro ejemplo del poder de los discursos hegemónicos en la creación de consenso en la opinión pública es el fracaso económico del diario Público, práctica más cercana al $15 \mathrm{M}$ y al periodismo cívico descrito por Alfaro (2005), al igual que otros proyectos de periodismo ciudadano con dificultades para mantenerse (como Periodismo Humano, por ejemplo).

50 Sin ir más lejos la campaña actual de la Fundación Vicente Ferrer cuyo discurso enfrenta dos opciones: "Apadrinar o Ignorar" (http://www.tuescoges.org/), discursos anquilosados en el modelo de gestión y asistencia que siguen distanciando el ellos del nosotros y no articulan una voz colectiva del nosotros. 
movimientos en torno al 15M, como NMS, se mueven en estos parámetros: "una comunicación $[\ldots]$ con un interés y enfoque público, social y solidario articulado en torno a la dinamización de una ciudadanía internacional guiada por la justicia social" (Nos Aldás y Pinazo, 2010: 110). Esta realidad comunicativa ha desbordado a las ONGD, que llevaban años mostrando su preocupación por la falta de énfasis en lo educativo y lo político de sus acciones comunicativas, responsabilizándose de la falta de activismo e implicación de la ciudadanía, y ha girado en $180^{\circ}$ la percepción de su responsabilidad y eficacia comunicativa, reclamando su revisión y reinvención como ONGD multiplicadoras de los discursos de estos NMS, que construyan redes dinámicas junto a ellos ${ }^{51}$. De ahí que los últimos estudios sobre la acción comunicativa de las ONGD desde la acción social reclamen organizaciones red como "modelo comunicacional para articular la diversidad de actores, de necesidades y de iniciativas" como alternativa al modelo burocrático y centralizado actual de las ONGD (García Roca, 2010: 48). ONGD-red para una sociedad-red (Santolino, 2010: 244).

Este trabajo es una primera exploración conceptual para plantear el seguimiento de cómo las ONGD evolucionan en los actuales escenarios de comunicación en interacción con las nuevas sociedades en movimiento (entre ellas la española y la onda expansiva de indignación y acción política pacífica en torno al $15 \mathrm{M})$ y de cómo estos agentes sociales trabajan en el reto de visibilizar nuevas narrativas (marcos virales) que desvelen y transformen los discursos hegemónicos reforzados desde las instituciones económicas, políticas, comunicativas y legislativas que legitiman las actuales estructuras de poder desigual. Una comunicación en esencia revolucionaria que se centra en los intereses de los ciudadanos (Chaparro, 2009: 156). Solo con el tiempo, otras investigaciones, sobre todo empíricas, que puedan extraer sus hipótesis de los planteamientos teóricos que este artículo propone, podrán comprobar con mayor distancia la eficacia y efectos de estos discursos contraculturales en las creencias sociales centrales y comprobar qué debates han quedado tan solo en tendencias virales y cuáles se han convertido en nuevos discursos sociales.

\footnotetext{
51 La falta de espacio nos obliga a generalizar. No obstante, por supuesto que en el 15M encontramos también muchos fallos comunicativos (habiéndonos centrado en los que aportaban algo a este estudio), mientras que sería interesante también un estudio más detallado de la influencia que el 15M ya ha tenido en las ONGD y sus escenarios de comunicación, como por ejemplo en Canal Solidario (que retoma el discurso de indignación por la crisis e interés por el cambio del $15 \mathrm{M}$ y lo vincula con el activismo y el voluntariado, dedicando un espacio especial a la movilización: “Crisis: ¡Actúa!” que enlaza a una página de "Información y recursos para pasar a la acción”" (http://www.canalsolidario.org/contenidos/especial-crisis/43). El discurso de esta plataforma de ONG se apoya en mensajes que promueven la participación y el empoderamiento de la ciudadanía (con lemas como “¡Actívate!”, “Pasa al activismo!”, “Inspírate”, “¿Y qué puedo hacer yo?” y “¡Reflexión-Investigación-Acción!”) y se concreta en mensajes claros con ideas para participar activamente con las ONG, como enlaces a oportunidades de voluntariado, ciberacciones, guías de ONG, noticias sobre activismo y crisis o espacios de debate para la construcción de un nuevo modelo, entre otros).
} 


\section{REFERENCIAS BIBLIOGRÁFICAS}

Acosta, A., E. Lander, E. Gudynas y otros (2009): El Buen Vivir. Una vía para el desarrollo. Quito: Abya-Yala.

Aladro Vico, E. (2011): "La Teoría de la Información ante las nuevas tecnologías de la comunicación”, CIC Cuadernos de Información y Comunicación, 16: 83-93.

Alberto PÉrez, R. (2003): “¿Por qué necesitamos una nueva teoría estratégica?”, en J. Benavides y N. Villagra García (eds.), Públicos, instituciones y problemas en la comunicación del nuevo milenio. Madrid: Fundación General de la Universidad Complutense.

Alfaro, R. M. (2005): "Sociedades en movimiento: desafíos comunicativos a la sociedad de la información", en J. Echevarría y otros (eds.), Solidaridad en red. Nuevas tecnologías, ciudadanía y cambio social. Bilbao: Hegoa: 57-79.

(1993): Una comunicación para otro desarrollo. Lima: Calandria

Aranguren Gonzalo, L. (2000): Reinventar la solidaridad. Voluntariado y educación. Madrid: PPC.

Austin, J. L. (1976): How to do things with words. Oxford: Oxford University Press.

Ballesteros, C. (2002): "Supermercados de la solidaridad" en L. Nieto, La ética de las ONG y la lógica mercantil. Barcelona: Icaria.

(2001): Marketing con causa, marketing sin efecto. El marketing con causa y la educación para el desarrollo. Madrid: U. Pontificia-ICADE.

BARnhurst, K. (2011): "The New "Media Affect" and the Crisis of Representation for Political Communication”, The International Journal of Press/Politics, 16 (4), octubre: 573-593.

BARRANQUERO, A. (2009): "The state of the art in citizens' communication for social change in Spain", Development in Practice, 19 (4-5): 643-653.

BENAVIDES, J. (2011): “La opinión pública y los medios de comunicación social”, en A. HorTAL y X. EtXeberria (eds.), Profesionales y vida pública. Bilbao: Descleé de Brouwer.

- (2002): "Los valores, los discursos y el conocimiento en el ámbito de la nueva cultura audiovisual y publicitaria", Revista de Ciencias de la Información, 11, 2001-2002. Valencia: Universidad Cardenal Herrera, CEU: 105-117.

(1997): Lenguaje Publicitario. Hacia un estudio del lenguaje en los medios. Madrid, Editorial Síntesis.

(1996): "Los escenarios de la comunicación mediática. Por una vía diferente de investigación”, Telos, 44, diciembre-febrero: 132-141.

_ (1994), "Sobre la "crisis" de la publicidad: ¿estrategias de adaptación a los cambios o una nueva manera de pensar?", en J. BENAVIDES (ed.), La crisis de la publicidad. Madrid: Edipo.

- (1993): "Dimensiones conceptuales de la comunicación corporativa", Revista de Ciencias de la Información, 7.

—. (1992): "Publicidad y conocimiento. Un debate para la investigación de la comunicación pública”, en J. Benavides, J. E. NeBOt, y R. A. PÉREZ (eds.), La comunicación en la Europa del 93. Madrid: Edipo.

(1991): "En torno a la filosofía de la comunicación", en La comunicación. Madrid: UPC: $3-60$.

Blackmore, S. (2000): La máquina de los memes. Barcelona: Editorial Paidós.

Boltanski, L. (2000): Lo spettacolo del dolore. Milán: Raffaello Cortina Editore.

Burgui, T. (2011): "Repensar las relaciones entre sociedad y Tercer Sector", en el III Congreso del Tercer Sector Social: Sumamos valores, construimos futuro, marzo, Barcelona. 
Calle Collado, Á. (2000): Ciudadanía y solidaridad. Las ONG de solidaridad Internacional como Movimiento Social. Madrid: IEPALA Editorial.

Castells, M. (2009): Comunicación y poder. Madrid: Alianza Editorial.

(1998): La era de la información. Economía, sociedad y cultura. Madrid: Alianza Editorial.

Chaparro, M. (2009): “Comunicación para el empoderamiento y comunicación ecosocial. La necesaria creación de nuevos imaginarios, perspectivas de la comunicación", Perspectivas de la Comunicación, 2 (1), Universidad de La Frontera, Temuco, Chile: 146-158.

Chomsky, N. y E. S. Herman (1995): Los guardianes de la libertad. Barcelona: Grijalbo Mondadori.

Cohen, S. (2001): States of denial. Cambridge: Polity Press

Comins Mingol, I. y V. Martínez GuzMán (2010): "Cultura de paz y educación para el desarrollo", en, J. ERro y T. Burgui (eds.), Comunicando para la solidaridad y la cooperación. Pamplona: Foro Comunicación, Educación y Ciudadanía: 51-70.

CONCORD y otros (2007): The European Consensus on Development: The contribution of Development Education \& Awareness Raising. Disponible en: http://ec.europa.eu/development/icenter/repository/DE_Consensus-eductation_temp_EN.pdf. [Consultado el 8 de marzo de 2012].

Congde (1998): "Código de conducta de las ONG de Desarrollo de la coordinadora de ONGD_España”. Disponible en: http://www.congde.org/ant/codigo_con.htm [Consultado el 8 de marzo de 2012].

Curran, J. (2005): Medios de comunicación y poder. Barcelona: Hacer.

DARnTON, A. y M. KIRK (2011): "Finding Frames: New ways to engage the UK public in global poverty". Informe. Bond for International Development. http://www.findingframes.org/Finding $\% 20$ Frames $\% 20$ New $\% 20$ ways $\% 20$ to $\% 20$ engage $\% 20$ the $\% 20$ UK $\% 20$ public\%20in\%20global\%20poverty\%20Bond\%202011.pdf [Consultado el 9 de marzo de 2012].

De SouzA, R. (2009): “Creating "Communicative Spaces": A Case of NGO Community Organizing for HIV/AIDS Prevention”, Health Communication, 24 (8): 692-702.

Deleuze, G. y F. Guattari (1988): Mil mesetas: capitalismo y esquizofrenia. Valencia: PreTextos.

Democracia Real Ya (2011): "Manifiesto". Democracia Real Ya. Disponible en: http://www.democraciarealya.es/manifiesto-comun/ [Consultado el 23 de febrero de 2012].

Development Education Exchange in Europe Project (DEEEP) (2006): The Code of Conduct on Images and Messages

http://www.deeep.org/images/stories/DARE/CodeofConduct/code $\% 20$ of\%20conduct\%20on\%20messages\%20and\%20images.pdf [Consultado el 8 de marzo de 2012].

DíAz Bordenave, J. (1978): “Aspectos políticos e implicaciones políticas de la comunicación participatoria”. Documento presentado al Primer Seminario Latinoamericano de Comunicación Participatoria. Quito: CIESPAL.

DíAz-SAlAZAR, R. (2011): “¿De dónde vienen y hacia dónde van las ONG?”, en el Curso Liderazgo e Innovación en las ONG, Barcelona, Fundación La Caixa-ESADE, 26 de mayo.

DogRA, N. (2007): "Reading NGOs Visually - Implications of visual images for NGO management”. Journal of International Development, 19: 161-171

Entman, R. M. (2007): "Framing Bias: Media in the Distribution of Power", Journal of Communication, 57 (1): 163-173. 
(2004): Projections of power: framing news, public opinion, and U.S. foreign policy. Chicago: University of Chicago Press.

Erro SAlA, J. (2010): “Comunicación, cooperación internacional para el desarrollo y ONGD: un modelo de trabajo desde la educación y la cultura?", en J. Erro Sala y T. Burgui (eds.), Comunicando para la solidaridad y la cooperación. Cómo salir de la encrucijada. Pamplona: Foro de Comunicación, Educación y Ciudadanía: 137-177.

(2007):“"ONGD: ¿reinventarse como Movimientos Sociales?”, Hika, 185, febrero: 37-38.

(2006): “¿Pensar la comunicación o revisar el modelo de organizaciones no gubernamentales para el desarrollo (ONGD)?”, en E. Nos AldÁs y M.a J. GÁmEZ Fuentes (eds.), Medios de comunicación y solidaridad: reflexiones en torno a la (des)articulación social. Castellón: Servei de Publicacions de la Universitat Jaume I: 89-106.

- (2003a): Descubrir y construir procesos de comunicación social (Herramientas). Bilbao: Hegoa.

(2003b): "ONGD: ¿comunicarse por qué y para qué? El paso de la comunicación mercadeada a la comunicación social educativa", en V. J. BENET y E. Nos AldÁs (eds.), La publicidad en el Tercer Sector. Tendencias y perspectivas de la comunicación solidaria. Barcelona: Icaria: 53-81.

- (2002): "El estallido de las fronteras entre la solidaridad y la cooperación para el desarrollo: ¿amenaza o nueva oportunidad para las ONGD?”, en Palabras para cambiar el mundo. Bilbao: PTM-Mundubat: 241-256.

. (2000): "Las prácticas comunicativas de las ONGD. De la comunicación mercadeada a la construcción de una mirada comunicacional", en Directorio de ONGD 2000. Madrid: CONGDE.

Erro Sala, J. y J. Ventura (2002): El trabajo de comunicación de las ONGD en el País Vasco. Bilbao: Hegoa (EHU-UPV).

Erro Sala, J. y T. Burgui (2010): Comunicando para la solidaridad y la cooperación. Cómo salir de la encrucijada. Pamplona: Foro de Comunicación, Educación y Ciudadanía.

Federación Catalana de ONGD (FCONGD) (1997): Código ético y de conducta. Barcelona: FCONGD.

Fernández GonzÁlez, J., C. Sevilla Alonso y M. Urbán Crespo (2012): “Introducción: ¡indignados del mundo, uníos!”, ¡Ocupemos el mundo! Occupy the world! Barcelona: Icaria.

FERRES I PRATS, J. (2010): “Comunicar y educar desde la cultura audiovisual”, en J. ERRO Sala y T. Burgui (eds.), Comunicando para la solidaridad y la cooperación. Cómo salir de la encrucijada. Pamplona: Foro de Comunicación, Educación y Ciudadanía: 1011-110.

Freire, P. (2001): Pedagogía de la indignación. Madrid: Morata.

(1993): Pedagogía de la esperanza: un reencuentro con la pedagogía del oprimido. Madrid: Siglo XXI.

Galtung, J. (2003): Paz por medios pacificos. Paz y conflicto, desarrollo y civilización. Gernika: Bakeaz-Gernika Gogoratuz.

- (1996): "Cultural Violence", en Peace by Peaceful Means. Londres: Sage Publications. (1990): "Cultural Violence”, Journal of Peace Research, XXVII (3): 291-305.

Gans, H. (1979): Deciding what's news. New York: Pantheon.

García CANClini, N. (2010): “De qué hablamos cuando hablamos de resistencia?”, Estudios Visuales, 7. Disponible en:

http://www.estudiosvisuales.net/revista/pdf/num7/02_canclini.pdf [Consultado el $20 \mathrm{de}$ abril de 2012]. 
García Roca, J. (2010): “Acción social y Comunicación”, en J. Erro SAla y T. Burgui (eds.), Comunicando para la solidaridad y la cooperación. Cómo salir de la encrucijada. Pamplona: Foro de Comunicación, Educación y Ciudadanía: 25-50.

GINER, S. y S. SARASA (1995): “Altruismo cívico y política social”, Leviatan, 61, otoño: 7186.

GiRÓ, X. (2010): “Discursos y grietas en política: la lógica de los actores, los límites de los medios y las metas periodísticas", en I. CAMACHO MARKINA (coord.), La especialización en periodismo. Formarse para informar. Salamanca: Comunicación Social: 75-95.

(2007): "Enfoques analíticos críticos sobre el discurso de la cobertura informativa de conflictos", en T. Telleschi y E. A. SAndoval Forero (coords.), Espacio y tiempo en la globalización. Una visión de la transparencia en la información, Università di Pisa y Comisión Estatal para el Acceso a la Información Pública del Estado de Sinaloa, Toluca (México): 199-220.

(1998): "La información sobre el Sur y el fenómeno de las grietas", Voces y culturas, 14 (II semestre): 57-79.

Gramsci, A. (1971): Selections from the Prison Notebooks. Nueva York: International Publishers.

GramsCI, A. Y D. Forgacs (2000): The Gramsci reader: selected writings, 1916-1935. Nueva York: New York University Press.

Grice, H. P. (1989): Studies in the way of words. Cambridge: Harvard University Press. (1975): "Logic and conversation" en P. Cole, y J. L. Morgan (eds.), Syntax and semantics, 3, Speech Acts. Nueva York: Academic Press: 41-58.

Gumucio, A. Y T. TuFTe (2008): Antología de comunicación para el cambio social: lecturas históricas y contemporáneas. Bolivia: Consorcio de Comunicación para el cambio social.

Habermas, J. (1994): Historia y crítica de la opinión pública. Barcelona: Gustavo Gili. (1987): Teoría de la acción comunicativa. Madrid: Taurus.

HALl, S. (2004): "Foucault: power, knowledge and discourse" WeTherell M, TAYLOR S, YATES S (eds.), Discourse Theory and Practice. A Reader. Londres: Sage Publications: $72-81$.

(ed.) (1997): Representation: Cultural Representations and Signifying Practices. Londres: Sage Publications.

Hallin, D. y P. Mancini (2004): Comparing Media Systems. Cambridge: Cambridge University Press.

Halloran, J. (1997): "International Communication Research: Opportunities and Obstacles", en A. Mohammadi (ed.), International Communication and Globalization. Londres: Sage Publications: 21.

HARDT, M. Y A. NegRi (2004): Multitud: guerra y democracia en la era del Imperio. Barcelona: Editorial Debate.

Haro BARBA, C. y V. SAMPedro (2011): “Activismo político en Red: del Movimiento por la Vivienda Digna al 15M", Revista Teknokultura, 2 (8), diciembre: 167-185

Hessel, S. (2010): ;Indignaos! Un alegato contra la indiferencia y a favor de la insurrección pacífica. Barcelona: Ediciones Destino.

Kaldor, M. (2003): Global civil society. An answer to war. Cambridge: Polity Press.

KAPLÚN, M. (1985): El comunicador popular. Quito: CIESPAL.

LAKOFF, G. (2010): "Why it matters how we frame the environment", Environmental Communication: A Journal of Nature and Culture, 4 (1): 70-81. (2008): The Political Mind. New York, NY: Viking Books.

. (2004): Don't Think of an Elephant: Know Your Values and Frame the Debate. White River Junction, VT: Chelsea Green. 
LATOUCHE, S. (2008): La apuesta por el decrecimiento. Barcelona: Icaria-Antrazyt.

LeVy, P. (2007): Cibercultura. La cultura de la sociedad digital. Barcelona: Anthropos.

LÓPEZ REY, J. A. (2006): "Los medios de comunicación y ONGDS: La conformación de una nueva cultura corporativa en el sector solidario", Comunicación y sociedad civil, Documentación Social, 140 (enero-marzo): 39-56.

MARí SÁEZ, V. (2011): Comunicar para transformar, transformar para comunicar. Tecnologías de la información desde una perspectiva de cambio social. Madrid: Editorial Popular.

MARTín-BARBero, J. (2008): "Políticas de la comunicación y la cultura. Claves de la investigación”, Documentos CIDOB. Dinámicas interculturales, 11.

MARTínez AVIDAD, M. (2011): "Redes alternativas de comunicación, framing y la construcción del poder político", Obets. Revista de Ciencias Sociales, 6 (2): 269-291.

Martínez-Gómez, R. y M. LubetKin (2010): Comunicación y desarrollo. Pasos hacia la coherencia. Zamora: Comunicación Social ediciones y publicaciones.

Martínez Guzmán, V. (2005): Podemos hacer las paces. Bilbao: Desclée de Brouwer.

- (2003): "Discurso y sensibilización: entre la indignación y la esperanza", en V. J. Benet y E. Nos AldÁs (eds.), La Publicidad en el Tercer Sector: tendencias y perspectivas de la comunicación solidaria. Barcelona: Icaria.

(2001): Filosofía para hacer las paces. Barcelona: Icaria.

McCombs, M. E. (2004): Setting the agenda: The mass media and public opinion. Malden, MA: Blackwell.

McCombs, M. E. y D. L. SHAw (1972): “The agenda-setting function of mass media”. Public Opinion Quarterly, 36(2): 176-187.

Mesa, M. (2010): "Comunicación y Educación para el Desarrollo: una apuesta por la ciudadanía global”, en J. Erro SAla y T. Burgui (eds.), Comunicando para la Solidaridad y la Cooperación. Cómo salir de la encrucijada. Pamplona: Foro de Comunicación, Educación y Ciudadanía: 201-220.

"La educación para el desarrollo: evolución y perspectivas actuales", en A. Monclús Estella (coord.), Educación para el desarrollo y cooperación internacional. Madrid: UNICEF-E.Complutense.

Misturelli, F. y C. HefFernan (2012): "The shape of change: A memetic analysis of the definitions of poverty from the 1970s to the 2000s", Journal of International Development, 24 (supl. 1), enero: S3-S18.

MumBY, D. (1997): “The problem of hegemony: Rereading Gramsci for organizational communication studies", Western Journal of Communication, 61 (4), septiembre: 343-375.

- (1993): Narrative and Social Control. Critical perspectives. CA: Sage Publications.

NACHAWATI, L. (2012): “¿Qué podemos aprender las ONG de movimientos como la primavera árabe o el 15-M?”, en \#ParadigmáTIC@s: Comunicación y cultura digital en las ONG de Desarrollo, Coordinadora Española de ONGD. Disponible en:

http://desycom.files.wordpress.com/2012/02/culturadigital.pdf. [Consultado el 15 de abril de 2012].

Navarro, E. y A. García Matilla (2011): "Nuevos textos y contextos en la web 2.0. Estudios de caso relacionados con las revoluciones en el norte de África y Oriente próximo", Cuadernos de Información y Comunicación, 16: 149-165.

NieTO, L. (Coord.) (2002): La ética de las ONGD y la lógica mercantil. Barcelona: Icaria.

Nos AldÁs, E. (2010): "Comunicación, cultura y educación para la solidaridad y el desarrollo", en J. Erro Sala y T. Burgui (eds.), Comunicando para la Solidaridad y la Cooperación. Cómo salir de la encrucijada. Pamplona: Foro de Comunicación, Educación y Ciudadanía: 113-135. 
(2007): Lenguaje Publicitario y Discursos Solidarios. Eficacia Publicitaria, ¿Eficacia Cultural? Barcelona: Icaria.

(2003): "Discurso publicitario y sensibilización en las ONGD: de la función social de la publicidad a la responsabilidad de la comunicación social", en V. J. BENET Y E. NOS AldÁs (eds.), La publicidad en el Tercer Sector: tendencias y perspectivas de la comunicación solidaria. Barcelona: Icaria: 83-128.

Nos Aldas, E., S. Segui-Cosme y A. Rivas Machota (2008): Comunicación y construcción de Paz. Barcelona: Icaria.

Nos Aldás, E. y D. PinAzo (2012): Versión Beta. "Developing Moral Sensitivity through Protest Scenarios in International NGDOS Communication", Communication Research. Disponible en: http://www.iudesp.uji.es/investigacion/publicaciones/versiones-beta [Consultado el 10 de abril de 2012].

- (2010): "La incógnita de la persuasión en la comunicación de las ONGD: hacia un modelo de publicidad culturalmente eficaz", Industrias da Persuassão. Covilhã, Portugal: Universidade da Beira Interior. Livros LabCom. Estudos em Comunicação: 87-122.

ORTEGA, P. (2011): “15M ¿Dónde estamos las ONG?”, www.hazloposible.org, 1 de junio de 2011. Disponible en: http://hazloposible.org/wp/15m-\%C2\%BFdonde-estamos-las-ong/ [consultado el 3 de marzo de 2012].

Ortega CARPio M. ${ }^{a}$ L. (2007): Estrategia de Educación para el Desarrollo de la Cooperación Española. Madrid: Ministerio de Asuntos Exteriores y de Cooperación.

- (2006):"Construyendo una ciudadanía global. Borrador para el balance de 19962006", III Congreso de Educación para el Desarrollo, Vitoria-Gasteiz, 7, 8 y 9 de diciembre de 2006, Hegoa.

O'Sullivan, T. y otros (1997): Conceptos clave en comunicación y estudios culturales. Buenos Aires: Amorrortu.

Pagola CARTe, J. (2009): Comunicación para el Desarrollo: La responsabilidad en la publicidad de las ONGD. San Sebastián: Diputación Foral de Guipúzcoa.

Reinsborough, P. y D. CAnning (2010): Re:Imagining Change. How to Use Story-based Strategy to Win Campaigns, Build Movements, and Change the World. Oakland, CA: PM Press/SmartMeme.

Requena Santos, F. (2008): Redes sociales y sociedad civil. Madrid: Centro de Investigaciones Sociológicas.

Revilla Blanco (ed.) (2002): Las ONG y la política. Madrid: Istmo.

RheIngold, H. (2002): Smart Mobs: The Next Social Revolution. Nueva York: NY: Perseus. Traducción en español RHEINGold, H. (2004): Multitudes inteligentes. La próxima revolución social. Barcelona: Gedisa Editorial.

Ridoux, N. (2008): Menos es más. Introducción a la filosofía del decrecimiento. Lince: Madrid.

RiechmANn, J. y F. FERnÁNDEZ Buey (1994): Redes que dan libertad. Introducción a los nuevos movimientos sociales. Barcelona: Paidós.

RizZARDINI, M. (2002): "La producción de conocimiento y comunicación de las ONGD. Entre la ideología dominante y un imaginario social alternativo", en M. REVILLA Blanco (ed.), Las ONG y la política. Madrid: Istmo.SAiz EchEZARRETA, V. (2009): "La solidaridad, espacio de mediación de los sentimientos morales. Análisis de la publicidad de las ONGD", Tesis doctoral. Universidad Complutense de Madrid, Facultad de Ciencias de la Información. Departamento de Periodismo III.

SAiz EchezARreta, V. (2008): "Resolución de la distancia moral a través de la mediación experta de las ONGD”, CIC: Cuadernos de información y comunicación, 13 (Ejemplar dedicado a: La mediatización del espacio público): 79-106 
SAMPEDro, V. (ed.) (2005): 13 M multitudes on line. Madrid: Los Libros de la Catarata.

SAMPEDro, V., A. Jerez y J. A. López Rey (2002): "ONGD, medios de comunicación y visibilidad pública. La ciudadanía ante la mediatización de los mensajes sociales", en $\mathrm{M}$. ReVILla Blanco (ed.), Las ONG y la política. Madrid: Istmo: 251-285.

SAMPEDro, V. y SÁnchez DuARTe, J.M. (2011): “La Red era la plaza". Epílogo en SAMPedro, V. (coord.). Cibercampaña. Cauces y diques para la participación. Las elecciones generales de 2008 y su proyección tecnopolítica. Madrid: UCM-Editorial Complutense.

SANTOLINO, M. (2010): "Recuperando la esencia: Las ONGD como agentes de comunicación para el cambio social" en J. ERro SAlA y T. Burgui (eds.), Comunicando para la Solidaridad y la Cooperación. Cómo salir de la encrucijada. Pamplona: Foro de Comunicación, Educación y Ciudadanía: 221-256.

SAVATER, F. (2000): Las preguntas de la vida. Barcelona: Ariel.

Scheufele, D. A. y D. Tewksbury (2007): "Framing, Agenda Setting, and Priming, The Evolution of Three Media Effects Models", Journal of Commnunication, 57 (1): 9-20.

SeCretaría TÉCNICA PlatAFORMa 2015 Y Más (2011): "Resumen de las Jornadas sobre eficacia del desarrollo: una mirada autocrítica al papel de las ONGD". Disponible en: http://www.2015ymas.org/spip.php?article546 [Consultado el 3 de marzo de 2012].

SEN, A. (2010): La idea de la justicia. Madrid: Taurus. : Desarrollo y libertad. Barcelona: Editorial Planeta.

ShePherd, S. Y A. C. KAY (2012): "On the Perpetuation of Ignorance: System Dependence, System Justification, and the Motivated Avoidance of Sociopolitical Information", Journal of Personality and Social Psychology, 102 (2): 264-280.

SMITH, M. (2008): "International non-governmental development organizations and their Northern constituencies: development education, dialogue and democracy”, Journal of Global Ethics, 4 (1): 5-18.

- (2004): "Mediating the world: development, education and global citizenship". Globalisation, Societies and Education, 2 (1): 1-24.

SogGe, D. (ed.) (1998): Compasión y cálculo. Barcelona: Icaria.

SPERBER, D. Y Wilson, D. (1986): Relevance. Communication and cognition. Oxford: Blackwell.

Vizer, E. A. (2003): "Prólogo", La trama (in)visible de la vida social: comunicación, sentido y realidad. Buenos Aires: La Crujía.

WITTEBORN, S. (2010): "The role of transnational NGOs in promoting global citizenship and globalizing communication practices", Language and intercultural communication, 10 (4): 358-372.

Zunzunegui Díez, S. (1999): "Publicidad, consumo y comportamiento", en J. L. Arceo Vacas, Tratado de Publicidad y Relaciones Públicas. Madrid: ICIE-Universidad Complutense de Madrid: 509-539. 


\title{
RESUMEN
}

Los movimientos sociales actuales han mostrado dinámicas comunicativas que pueden servir como referente para el desarrollo de una eficacia cultural en la comunicación de las ONGD. Esta eficacia se refiere a la responsabilidad de los discursos de estas organizaciones en la formación de ciudadanías críticas globales, objetivo de la Comunicación y la Educación para el Desarrollo. Este artículo revisa el concepto de Comunicación para el Desarrollo desde dicho proyecto pedagógico y define las ONGD como agentes comunicativos para el cambio social que buscan transformar los movimientos sociales en "sociedades en movimiento" (Alfaro 2005: 57-80). Mediante el análisis de la acción comunicativa de los movimientos de "indignados" del 15M desde su impacto cultural, proponemos un soporte teórico para la renovación del trabajo comunicativo de las ONGD.

Palabras clave: Comunicación, desarrollo, cambio social, educación, eficacia cultural, nuevos movimientos sociales, $15 \mathrm{M}$, discursos, ONGD.

\begin{abstract}
New social movements have employed communicative dynamics that can serve as a reference for developing cultural efficacy in the communication practices of NGODs. This efficacy relates to the responsibility of the discourses of these organizations in the development of critical global citizenships, a goal of Communication and Education for Development. This article revises the concept of Communication for Development from this pedagogical project and defines NGODs as communicative agents for social change who seek to transform social movements into "societies on the move" (Alfaro, 2005: 57-80). By analysing the communicative action of the $15 \mathrm{M}$ "indignant" movements from its cultural impact, we provide a theoretical base for the renovation of the communicative work of NGODs.
\end{abstract}

Key words: Communication, development, social change, education, cultural efficacy, new social movements, $15 \mathrm{M}$, discourse, NGOD.

\section{RÉSUMÉ}

Des mouvements sociaux actuels ont montré la dynamique de communication que peut servir de référence pour l'élaboration d'une efficacité culturelle dans la communication de l'ONG. Cette efficacité se réfère à la responsabilité des discours de ces organisations dans la formation des citoyennetés critiques globales, objet de communication et d'éducation pour le développement. Cet article examine le concept de communication pour le développement du projet pédagogique et définit l'ONG comme agents de communicationnels pour le changement social qui visent à transformer des mouvements sociaux dans les " sociétés en mouvement" (Alfaro 2005:57-80). Grâce à l'analyse de l'action communicative des mouvements des "indignés" de $15 \mathrm{M}$ et de son impact culturel, nous proposons un support théorique pour le renouvellement du travail de l'ONG communicative.

Mots clé: Communication, développement, changement social, l'éducation, l'efficacité culturelle, nouveau discours de $15 \mathrm{M}$, les mouvements sociaux, ONG. 